\title{
Deformation bands in porous carbonate grainstones: Field and laboratory observations
}

\author{
Antonino Cilona ${ }^{\mathrm{a}, *}$, Patrick Baud ${ }^{\mathrm{b}}$, Emanuele Tondi ${ }^{\mathrm{a}}$, Fabrizio Agosta ${ }^{\mathrm{c}}$, Sergio Vinciguerra ${ }^{\mathrm{d}}$, \\ Andrea Rustichelli ${ }^{\mathrm{a}}$, Christopher J. Spiers ${ }^{\mathrm{e}}$ \\ ${ }^{a}$ Geology Division, School of Science and Technology, University of Camerino, 62032 Camerino, MC, Italy \\ ${ }^{\mathrm{b}}$ EOST Strasbourg, Université de Strasbourg/CNRS, UMR 7516, France \\ ${ }^{\mathrm{c}}$ Department of Geological Sciences, University of Basilicata, Italy \\ ${ }^{\mathrm{d}}$ Department of Earth Sciences, University of Turin, Italy \\ e Utrecht University, Faculty of Geosciences, HPT Laboratory, Utrecht, The Netherlands
}

\section{A R T I C L E I N F O}

\section{Article history:}

Received 6 November 2011

Received in revised form

20 March 2012

Accepted 26 April 2012

Available online $\mathrm{xxx}$

\section{Keywords:}

Limestones

Deformation processes

Micromechanics

Wet conditions

Brittle-ductile transition

\begin{abstract}
A B S T R A C T
Recent field-based studies documented deformation bands in porous carbonates; these structures accommodate volumetric and/or shear strain by means of pore collapse, grain rotation and/or sliding. Microstructural observations of natural deformation bands in carbonates showed that, at advanced stages of deformation, pressure solution helps to reduce the grain size, enhancing comminuted flow and forming narrow cataclastic zones within the bands. In contrast, laboratory studies on the mechanics of deformation bands in limestones identified grain crushing, pore collapse and mechanical twinning as the micromechanisms leading to strain localization.

Here, we present a multidisciplinary field and laboratory study performed on a Cretaceous carbonate grainstone to investigate the microprocesses associated to deformation banding in this rock. A quantitative microstructural analysis, carried out on natural deformation bands aimed at defining the spatial distribution of pressure solutions, was accompanied by a force chain orientation study. Two sets of triaxial experiments were performed under wet conditions on selected host rock samples. The deformed samples often displayed a shear-enhanced compaction behavior and strain hardening, associated with various patterns of strain localization.

We constrained the pressure conditions at which natural deformation bands developed by reproducing in laboratory both low and high angle to the major principal stress axis deformation bands. The comparison among natural and laboratory-formed structures, allowed us to gain new insights into the role, and the relative predominance, of different microprocesses (i.e. microcracking, twinning and pressure solution) in nature and laboratory.
\end{abstract}

(c) 2012 Elsevier Ltd. All rights reserved.

\section{Introduction}

The inelastic deformation of porous rocks is a widely studied problem among the scientific community. The specific failure modes, faulting processes and overall strain rates are all aspects that are currently investigated by both field and laboratory studies with the purpose of better assessing the control exerted by deformation on the petrophysical properties of porous rocks in geotechnical engineering and reservoir management applications (see Fossen et al., 2007; for a full review). In fact, both natural and laboratory-induced modifications of pore volume, shape and,

\footnotetext{
* Corresponding author.

E-mail address: antonino.cilona@unicam.it (A. Cilona).
}

hence, interstitial pressure in the subsurface may cause variations of the effective stress possibly leading to faulting and/or inelastic deformation, as well as alter the original fluid flow paths in the shallow crust (see Faulkner et al., 2010 for a full review). In recent years, Tondi et al. (2006) and Tondi (2007) described a new faulting mechanism characteristic of porous limestones. By means of detailed field and microstructural observations, four main deformation processes representative of increased stages of deformation were identified: (i) compaction and shear strain localization into narrow bands (Aydin, 1978; Antonellini et al., 1994; Antonellini and Aydin, 1994; Shipton and Cowie, 2001; Aydin et al., 2006; Rath et al., 2011), (ii) pressure solution at the grain contacts, with development of discrete pressure solution seams, within the already compacted bands (Rutter, 1983; Groshong, 1988; Liteanu

0191-8141/\$ - see front matter @ 2012 Elsevier Ltd. All rights reserved. doi:10.1016/j.jsg.2012.04.012 
and Spiers, 2009; Croizé et al., 2010c; Zhang et al., 2010), (iii) subsequent shearing of the pressure solution seams (e.g. Alvarez et al., 1978; Agosta and Aydin, 2006; Agosta et al., 2009) and (iv) cataclasis localized along the sheared pressure solution seams (e.g. Engelder, 1974).

In the laboratory, the mechanical behavior of carbonate rocks of a wide range of porosities has been documented by many studies (Fruth et al., 1966; Teufel et al., 1991; Renner and Rummel, 1996; Fabre and Gustkiewicz, 1997; Baud et al., 2000, 2009; Vajdova et al., 2004; Risnes et al., 2005; Zhang and Spiers, 2005; Baxevanis et al., 2006; Croizé et al., 2010a, b; Zhu et al., 2010; Dautriat et al., 2011; Vajdova et al., in press). These studies investigated the distinct mechanical responses of carbonates to different stress conditions and various level of plastic strain. By monitoring the evolution of deformation, the aforementioned authors deduced that carbonates with intermediate values of porosity (3-18\%) display dilatancy and shear localization in dry conditions and at low confining pressure. Differently shear-enhanced compaction and strain hardening are the prevailing mechanisms at higher confining pressures. After a certain amount of strain hardening (this amount typically increases with confining pressure), a switch from compaction to dilatancy is observed (Baud et al., 2000; Vajdova et al., 2004). The high-porosity carbonates $(\varphi>30 \%)$ studied in Baud et al. (2009) show similar behavior to the less porous ones, but no dilatancy occurs at low confining pressures. The results of microstructural analyses performed, on the laboratory deformed samples, by previous authors highlighted microcracking and plastic/cataclastic pore collapse as the main deformation micromechanisms. Moreover, since calcite requires relatively low shear stresses to initiate mechanical twinning and dislocation, these latter mechanisms play also a significant role in particular at high levels of plastic strain (Vajdova et al., 2010, in press). The complex interplay between pore collapse, microcracking and crystal plasticity hence controls the carbonates macroscopic compactive yielding (Vajdova et al., 2004, 2010, in press; Zhu et al., 2010).

While previous studies have shown that natural and laboratory deformation bands have comparable characteristics (i.e. pore and grain sizes reduction), many discrepancies among the mechanisms responsible for their development have been found. The comparison between field and laboratory failure processes remains to date limited by the fact that most experimental studies on carbonates have been performed on dry rocks whereas the natural deformation (i.e. compaction, pressure solution) likely happens in presence of fluids.

In this paper we present the results of a multidisciplinary work, which integrates field and laboratory studies on the porous carbonate grainstones belonging to the Orfento Formation (Vecsei, 1991; Mutti et al., 1996). The goal is to gain a new knowledge on the micromechanics of deformation bands in porous carbonates.

\section{Geological setting, lithological description and rocks characterization}

The Majella Mountain is an East-vergent, thrust-related anticline located in the external zone of the central Apennines, in central Italy (Fig. 1; Vezzani and Ghisetti, 1998). The stratigraphic succession includes a $2 \mathrm{~km}$-thick sequence of Cretaceous to Miocene carbonate units, which are related to different depositional settings (platform and slope/ramp) originally pertaining to the northernmost sector of the Apulian Platform realm. The Apulian carbonate units are overlain by siliciclastic deposits of Messinian-to-Pleistocene age originally deposited within the PeriAdriatic foredeep basin of the central Apennines fold-and-thrust belt (Scisciani et al., 2002). According to Ghisetti and Vezzani (2002) and Agosta et al. (2009), the development of the Majella thrust-related anticline occurred during the Middle-to-Late Pliocene. The internal deformation of this box-shaped fold, characterized by two highly-steeping to overturned limbs, mainly consists of high-angle normal, strike-slip and oblique-slip faults, small folds and different sets of fractures (e.g. Marchegiani et al., 2006; Tondi et al., 2006; Antonellini et al., 2008; Agosta et al., 2010; Aydin et al., 2010).

This study focuses on natural and laboratory deformation bands of the Upper Campanian to Maastrichtian Orfento Fm. (Vecsei, 1991). This formation consists of white, high porosity and friable bioclastic grainstones rich of rudist fragments interpreted as a package of proximal bioclastic turbidites (Mutti et al., 1996). The study area corresponds to a small quarry named Madonna della Mazza, which is located in the inner part of the Majella anticline's forelimb nearby the town of Pretoro (Fig. 1; see also Tondi et al., 2006). By means of stratigraphic and sedimentological analyses, of different parameters (e.g. measurement of bed thickness and lateral extension, grain size estimation by comparison charts), we were aimed at better defining the depositional architecture of the studied rocks. Samples collection of the most representative strata (see Fig. 2 and Table 1) was carried out for: thin section observations, porosity measurements (i.e. water saturation method and helium pycnometer) and rock mineralogical composition by means of x-ray diffraction analysis. Sclerometric testing, performed by using a Proceq L/LR-type Schmidt Hammer, allowed us to estimate the mechanical properties, namely the unconfined Uniaxial Compressive Strength (UCS), of the sampled strata (Table 1). Even if the provided results are only an estimation of UCS, on the other hand this instrument is a very expeditious test that can be directly performed in the field by applying the standard measurement procedure (http://www.abbeyspares.co.uk): twenty rebounds are measured in correspondence of each station. The twenty obtained values are subsequently computed by discarding both the five higher most and lowermost readings, and then hence by averaging the 10 remaining values.

Our detailed stratigraphic/sedimentological loggings (Fig. 2) showed that the bulk of the Orfento Fm., exposed at the Madonna della Mazza quarry, is made up of poorly-cemented, whitish bioclastic carbonate grainstones (sensu Dunham, 1962; Table 1).

The studied carbonate grainstones are arranged into normal graded, planar beds gently dipping toward NE with dip angle of about $18^{\circ}$ showing erosional bases, lateral extensions up to $10 \mathrm{~s}$ of meters and thickness of tens of decimeters (Fig. 3; Rustichelli, 2010). Centimeter-thick, strongly cemented layers of whitish calcilutites (mudstones, wackestones and packstones, sensu Dunham, 1962) are often present at the top of individual carbonate beds. Intraformational carbonate breccia horizons, up to tens of meterlong and reaching tens of centimeters of thickness, consist of subangular-to-sub-rounded rudist fragments (mainly Radiolitidae) and intraclasts dispersed into a fine- to very fine sand-grained bioclastic matrix.

According to the facies model proposed by Mutti et al. (1996), the large-scale planar geometry of beds, as well as the erosional bases and normal gradation of individual beds, represent the diagnostic elements that allowed us to interpret these carbonate rocks as a package of proximal bioclastic turbidites (Fig. 4). The lower portion of each individual turbidite bed is broadly constituted by decimeter-thick normally-graded grainstones, which gradually evolve upwards into centimeter-thick calcilutites.

Both bioclastic carbonate grainstones, which range in size from fine sand to silt, and intraformational carbonate breccias are constituted by predominant rudist fragments and intraclasts (Table 1; Fig. 4a and b). Rudist shells can be partially replaced by either micrite or detrital sparry calcite; on the contrary, intraclasts and calcilutites consist of micrite mixed to detrital microsparry 


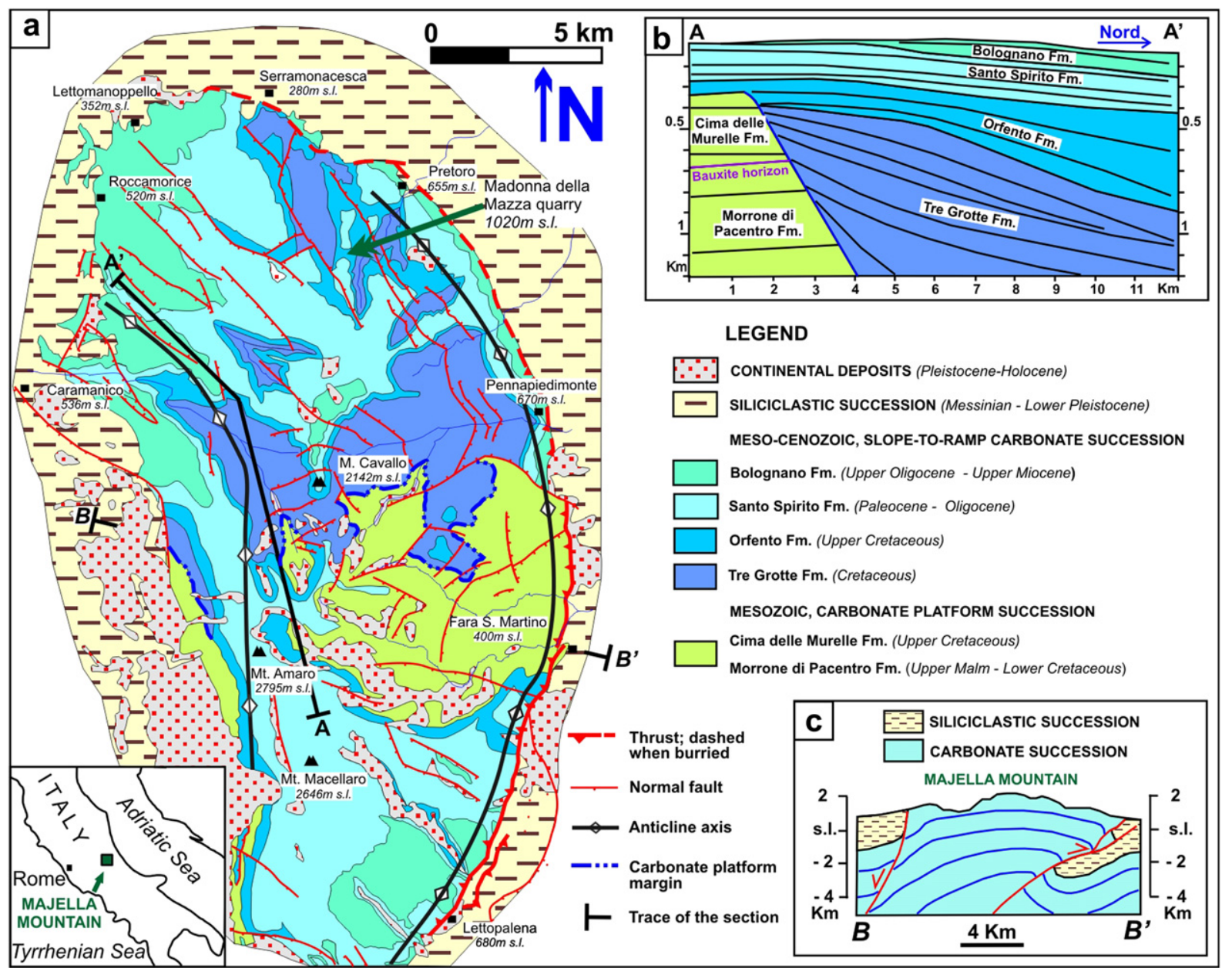

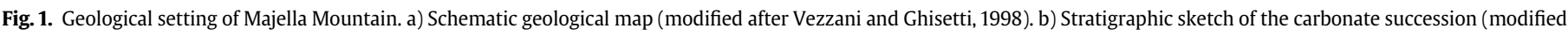
after Vecsei, 1991). c) Schematic geological section (modified after Scisciani et al., 2002).

calcite. The amount of microsparite clasts decreases upward, being responsible for the grading texture of calcilutites (from packstone to mudstone, Fig. 4c). Rare echinoid plates (Fig. 4b) and spines, as well as sporadic Orbitoides, are also present in the bioclastic grainstones and within the matrix of the intraformational carbonate breccias.

In thin section, the studied lithofacies are characterized by both intergranular and minor intragranular porosity (sensu Choquette and Pray, 1970), the pycnometer measurements gave us porosity values reaching up to $32 \%$ of the total rock volume (Table 1 ; consistent with Mutti, 1995; Tondi et al., 2006; Baud et al., 2009; Zhu et al., 2010; Vajdova et al., in press). The intragranular pores are mainly concentrated within rudist fragments (Fig. 4a).

A negligible amount of vuggy porosity $(<1 \%)$ is also present within both fine-grained carbonate grainstones and intraformational carbonate breccias, this last lithofacies is not the object of the present study. In thin section the very fine sand (S18 Low.) and siltgrained carbonate grainstones (S18 Upp. and S19), as well as the calcilutites (Table 1) present a quite uniform porosity because of many pores characterized by similar diameter sizes (S18 Low. $=60 \mu \mathrm{m} ; \mathrm{S} 19=20 \mu \mathrm{m}$ ) and shapes. On the contrary, in the fine sand-grained carbonate grainstones (S11 Upp. and S11 Low) and intraformational carbonate breccias (Table 1 ), pore diameters are more heterogeneous in size (S11 Upp. $=$ from $9 \mu \mathrm{m}$ to $75 \mu \mathrm{m}$; breccias from $15 \mu \mathrm{m}$ to $600 \mu \mathrm{m}$ ), shape and distribution. Pore throat statistics, determined from mercury injection on sample S18 Upp., shows a peak value centered at $16.2 \mu \mathrm{m}$ with no pore throat diameters $<0.2 \mu \mathrm{m}$ (Baud et al., 2009). Within all of the analyzed lithofacies, low amounts $(<2 \%)$ of microsparry calcite cement are present as thin discontinuous rims, which surround individual, intergranular and intragranular pores.

In Fig. 5 we provide some outcrop images of both natural compactive shear bands and compaction bands from Madonna della Mazza Quarry. Deformation bands (DBs) are easily recognizable in the field because they are lighter-colored with respect to the host rock and show a positive relief due to their better resistance to the erosion. In this work we focused on the microstructural analysis of four structural elements representing different stages of deformation. The sample location is highlighted by the colored boxes in Fig. 5. Further details on kinematics and dimensional attribute of these deformation bands can be found in Tondi et al. (2006).

\section{Natural deformation bands}

\subsection{Microstructural observations}

The quantitative textural and microstuctural analyses, presented in this section, extend the observations previously carried out by Tondi et al. (2006) on the natural DBs of Madonna della Mazza Quarry. By means of petrographic thin section observations (Figs. 6 and 7), performed by using both an optical polarizing microscope (Nikon Eclipse E600 Pol microscope) and a Field Emission Scanning Electron Miscroscope (FESEM), we analyzed the 


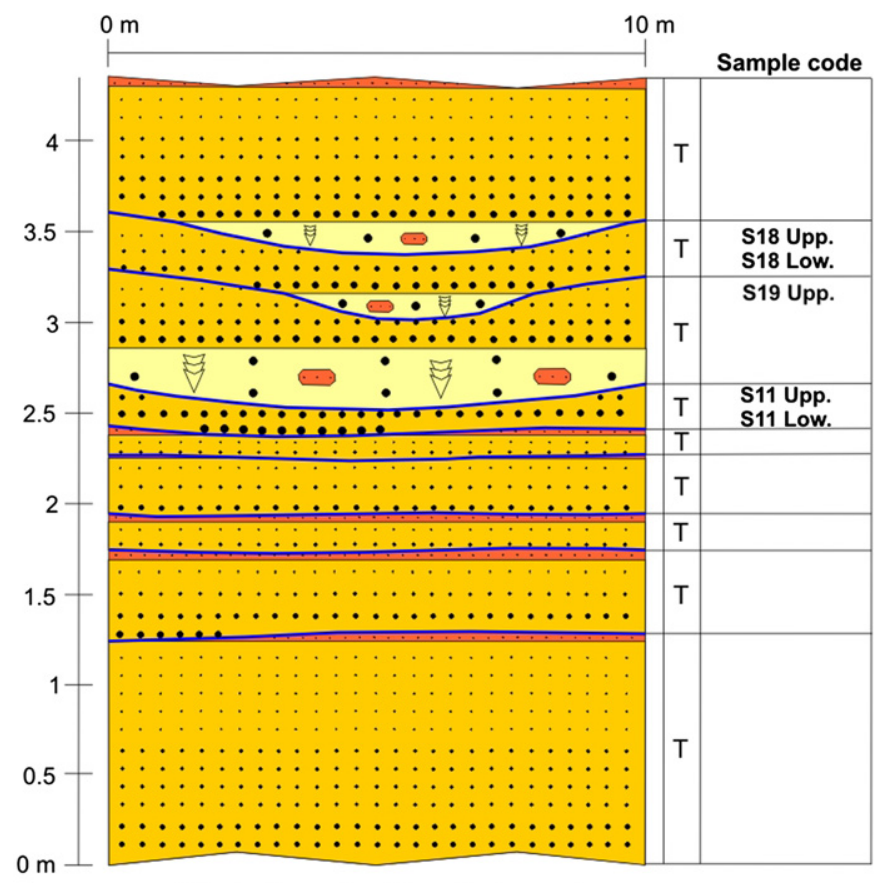

Orfento Formation (Upper Cretaceous)

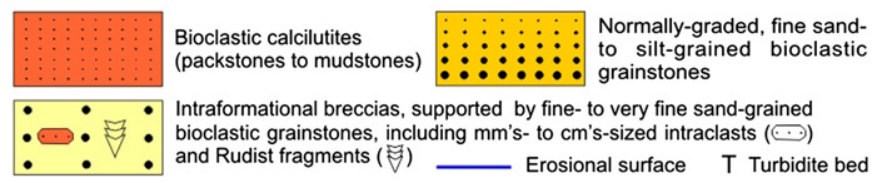

Fig. 2. Stratigraphic scheme of the carbonate succession analyzed for this study. This turbidite succession pertains to the Orfento formation and is exposed at both southern and western walls of the Madonna della Mazza Quarry. The sample location (refer to Table 1) along the stratigraphic succession is shown.

inner fabric of the DBs and assessed the micromechanisms responsible for their formation. A computer-based quantitative image analysis was carried out on redrawn microphotographs (pixel sizes from 0.5 to $2 \mu \mathrm{m}$ ), using the Image-J 1.32 software. We quantified the textural parameters (i.e. grain and pore sizes distribution, sorting) from the mean of the minimum and maximum Feret's diameters of the measured particles as well as the percentage of different rock components (i.e. grains, pores and matrix; see Table 2 and Fig. 9). The accuracy of the applied method is strongly dependent on the picture quality; on optical microscope pictures, we were able to measure only features (i.e. grains and pores) with the major axis longer than $10 \mu \mathrm{m}$. The sorting values of grain size and pore size distribution curves were calculated as the ratio between $D_{75}$ and $D_{25}$ (where the value $D_{75}$ represents a diameter size, which is longer than the $75 \%$ of the measured diameters, whereas $D_{25}$ represents a diameter size longer than the $25 \%$ of the measured diameters), the grain and pore size values are computed from the $\mathrm{D}_{50}$, which represents a diameter longer than
$50 \%$ of the measured diameters (Casadio and Elmi, 2006). We specifically focused on four representative structural elements cross cutting the strata, which were subsequently sampled for the deformation experiments (see Fig. 2 and Table 1): i) single deformation bands with negligible amount of cataclasis, occurring parallel or oblique with respect to bedding, ii) deformation bands with pressure solution and discontinuous pockets of cataclasis and iii) deformation bands characterized by continuous tabular zone of cataclasis overprinted by sheared pressure solutions.

The inner portions of the single deformation bands (Figs. 6 and 7) are characterized by low values of porosity, which range between 0.5 and $4 \%$ (Table 2; values for pores with the major diameter $>10 \mu \mathrm{m}$; see also Zhu et al. (2010)). Due to the porosity decreasing within the bands, and on the basis of the orientation of the kinematic vector (Aydin et al., 2006), the bed-parallel DBs are classified as compaction band $(\mathrm{CB})$, while the other five sets as compactive shear bands (CSB) (in agreement with Tondi et al., 2006). CBs and CSBs with negligible amount of cataclasis show a fitted-fabric, but they have maintained almost the same grain-to-matrix ratio with respect to the adjacent host rock (Table 2 ). Within the $\mathrm{CB}$, the grain size value $\left(D_{50}\right)$ is $65 \mu \mathrm{m}$, whereas in the host rock the grain size value is $75 \mu \mathrm{m}$. Pore size distribution curves show a notable pore size reduction, indeed within the $\mathrm{CB} \mathrm{D}_{50}=40 \mu \mathrm{m}$ and in the surrounding host rock the pore size is $62 \mu \mathrm{m}$ (Fig. 9). The grain size values, measured inside and outside the CSB with negligible quantities of cataclasis, are almost the same, in fact within the CSB $D_{50}$ is $75 \mu \mathrm{m}$ whereas in the host rock $D_{50}$ is $70 \mu \mathrm{m}$. The pore size distribution curves show a reduction of the size within the CSB: $\mathrm{D}_{50}=38 \mu \mathrm{m}$ with respect to the host rock where $\mathrm{D}_{50}=45 \mu \mathrm{m}$, which is mainly due to the collapse of the biggest pores (Fig. 9a).

The aforementioned results are in agreement with Tondi et al. (2006) and Tondi (2007) and confirm that pore collapse, due to grain rotation and sliding, was the earliest deformation micromechanism. Moreover, within deformation bands with negligible amount of cataclasis, we observed some indented grains and few dark discontinuities, interpreted as pressure solution (PSs; Figs. 6a, $7 \mathrm{a}$ and $8 \mathrm{c}, \mathrm{d}$ ) in agreement with the previous scanning electron microscope analyses of Tondi et al. (2006). Further detailed FESEM analyses within a CSB with negligible amount of cataclasis, allowed us to documented tiny ( $>100 \mu \mathrm{m}$, not discernible under optical microscope) Hertzian cracks (Zhang et al., 1990; Brzesowsky et al., 2011) at the grain contacts (Fig. 8 a-b). These cracks, only affecting the bands with negligible amount of cataclasis, reduce the grain size, and at the same time, are likely to enhance the pressure solution process by increasing the surface area of the rock (in agreement with experimental data of Zhang and Spiers 2005; Croizé et al., 2010c and Zhang et al., 2010). The occurrence of Hertzian cracks is the evidence that the CSBs nucleated within an already lithified rock (Fossen et al., 2007). On the other hand, due to a more abundant presence of PSs at the grain contacts with respect to cracks, we could classify the single DBs as "solution and cementation bands" (Fossen et al., 2007). The inner parts of some DBs are rimmed in both sides by an area, called 'boundary zone' by Antonellini and Aydin (1994) and by Tondi et al. (2006) or 'rim' in

Table 1

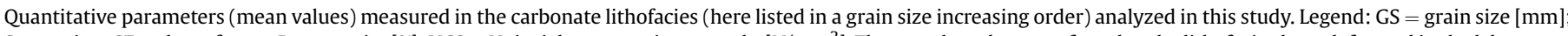

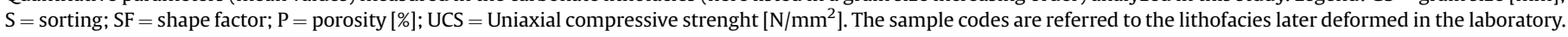

\begin{tabular}{|c|c|c|c|c|c|c|}
\hline Lithofacies & GS & $\mathrm{S}$ & SF & $\mathrm{P}$ & UCS & Sample code \\
\hline Calcilutites (packstones to mudstones) & 0.02 & 0.006 & 1.08 & 0.2 & 58 & \\
\hline Silt-grained grainstones & 0.05 & 0.015 & 1.14 & 30 & 53.75 & S19; S18 Upp. \\
\hline Very fine sand- to silt-grained grainstones & 0.08 & 0.023 & 1.13 & 31.89 & 45.25 & S18 Low. \\
\hline Very fine sand-grained grainstones & 0.11 & 0.045 & 1.14 & $30.5-32$ & 41.5 & S11 Upp.; S11 Low. \\
\hline Fine sand-grained grainstones & 0.14 & 0.069 & 1.16 & 29 & 37 & \\
\hline Intraformational breccias & $>0.14$ & 1 & 1 & 12.4 & 49.5 & \\
\hline
\end{tabular}




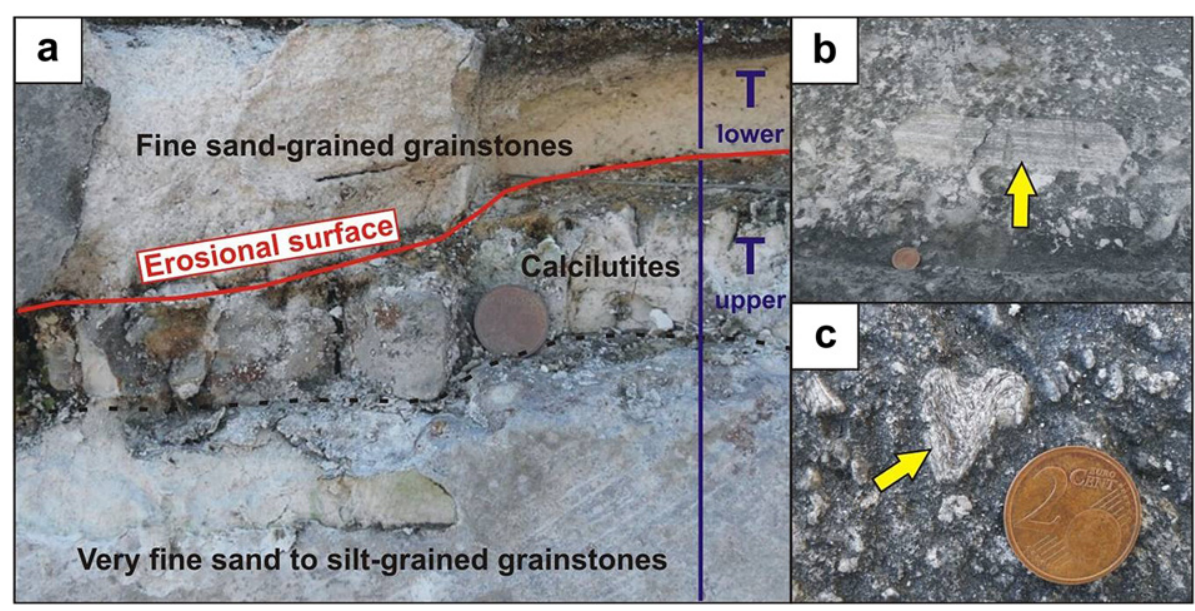

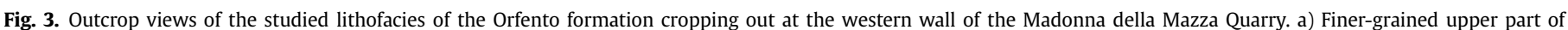

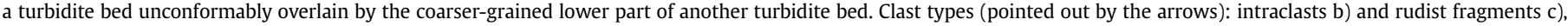
which constitute the intraformational breccias present at the bottom of a few turbidite beds.

Rath et al. (2011), in which the porosity decreases less than in the inner band itself (Fig. 6d). The CB also shows an incipient process of cementation within its 'rim' zone (Fig. 7). By means of FESEM, we also found "dissolution channels" (Fig. 8b) characterized by a decreasing width with depth. The formation of these channels can be related to fluids that moved along pre-existing cracks.

The grain-to-matrix ratio measured of the CSBs overprinted by intergranular PSs and discontinuous pockets of cataclasis is almost half of the ratio that characterizes the surrounding host rock (Fig. 6c, d and Table 2). Moreover, the grain size and pore size distribution curves of these CSBs show a notable reduction of the pore size (band $=38 \mu \mathrm{m}$; host rock $=70 \mu \mathrm{m}$ ) but a very low grain size reduction (band $=79 \mu \mathrm{m}$; host rock $=80 \mu \mathrm{m}$ ) due to dissolution (Fig. 9). The diminution of grain-to-matrix ratio and grain size observed within the CSBs, overprinted by PSs, could represent an incipient process of cataclasis (Fig. 6). Within these CSBs we document a higher frequency of intragranular PSs, some of which are sheared parallel to the bands The dissolution process localized within these CSBs allowed us to classify them as "solution and cementation band" (sensu Fossen et al., 2007).

The grain-to-matrix ratio, measured within the CSBs overprinted intragranular PSs and cataclastic material (Fig. 6 and Table 4), is almost four times less than in the surrounding parental rock. The grain size and pore size distribution curves show a notable reduction of both pore size and grain size (Fig. 9). In these bands we did not observe any evidence of grain crushing, in contrast with the observations on the CSBs with low amount of cataclasis and with the recent data provided by Rath et al. (2011) and Rustichelli et al. (2012).

Within the CSB overprinted intragranular PSs and cataclastic material, the process of cataclasis (Fig. 6f) appears more developed. Indeed, the inner part of the band presents a matrix-supported texture instead of a grain-supported one (see the isolated rudist fragment survived within a cataclastic zone; Fig. 6f). Band-parallel PSs present within the cataclastic CSBs appear sheared, as evidenced by the second set of short and poorly-developed bandoblique PSs (tail PSs). From both petrophysical and structural point of view, the above mentioned cataclastic zone is similar to the cataclastic deformation zones described in earlier studies (e.g. Aydin, 1978; Fossen et al., 2007). PSs (i.e. intergranular) are widely diffused in the CSBs, on the contrary (in agreement with Tondi et al., 2006), we documented mechanical twinning, similar to the experimental observations reported by Baud et al. (2009) and Vajdova et al. (2010) in porous limestones, only in few coarse calcite grains. The twinned calcite frequency seems not to be directly related with increased stages of deformation.

For each of the analyzed DBs, pressure solution density analysis was performed with the aim of characterizing their spatial distributions. A squared grid of $1 \mathrm{~mm}^{2}$ of area was superimposed on each analyzed microphotograph. Using stereological techniques (Wu et al., 2000), the number of pressure solution intersections with a test array of 10 parallel lines spaced at $0.1 \mathrm{~mm}$ was counted.

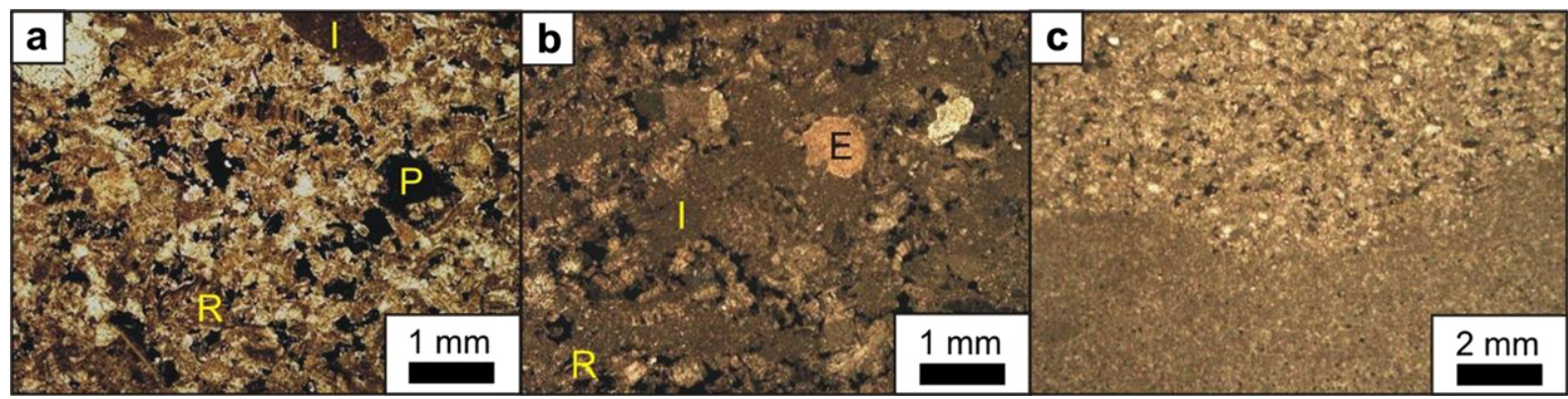

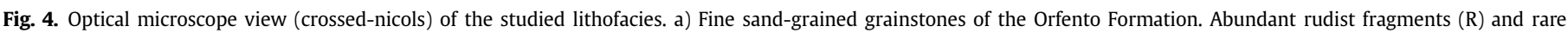

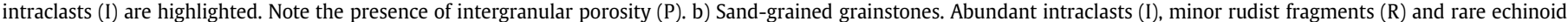

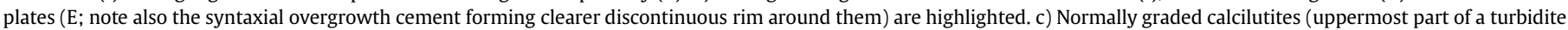
bed) unconformably overlied by very fine sand-grained grainstones (lowermost part of a turbidite bed). 

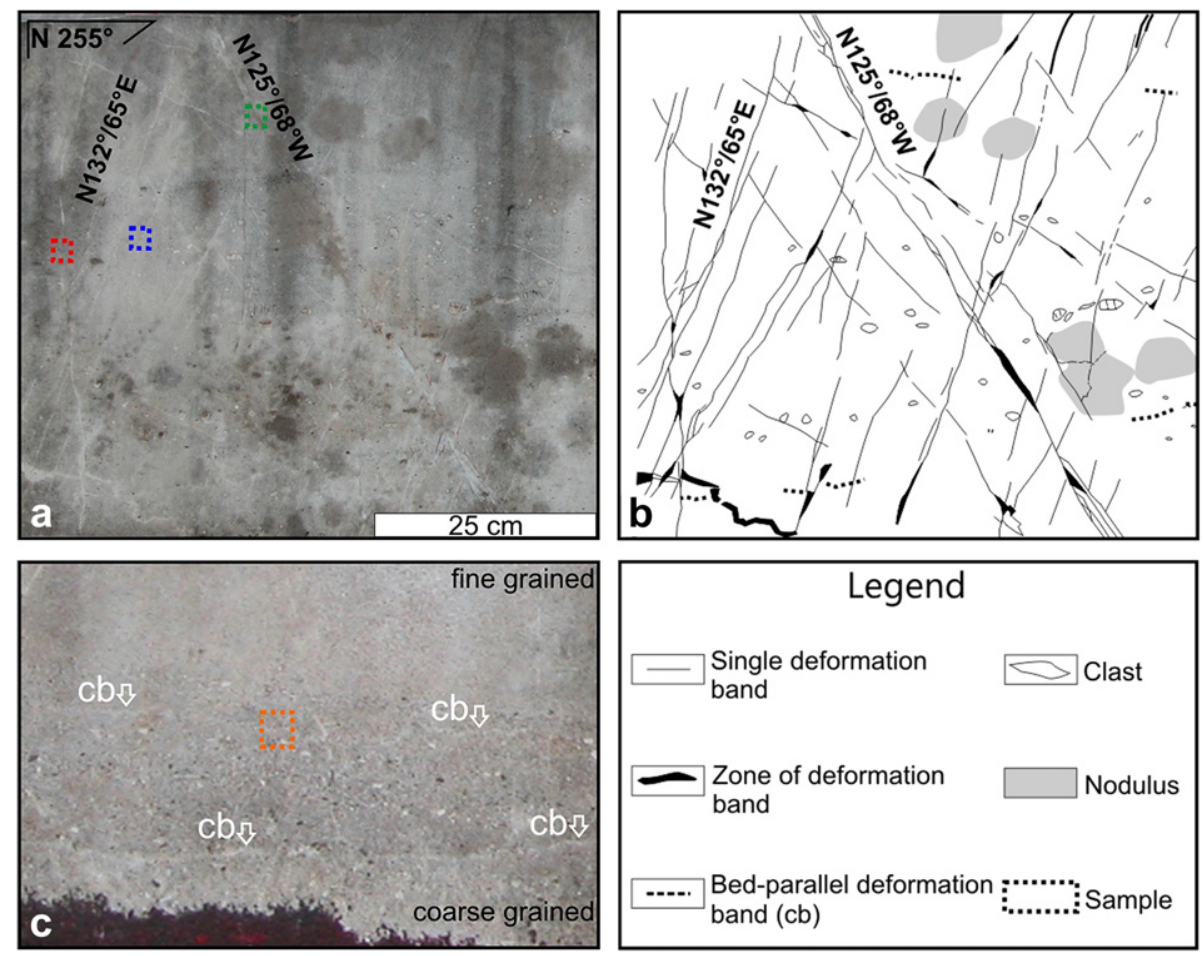

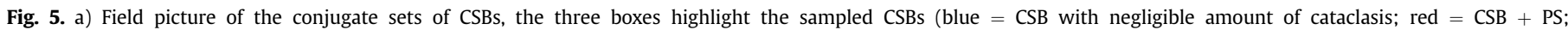

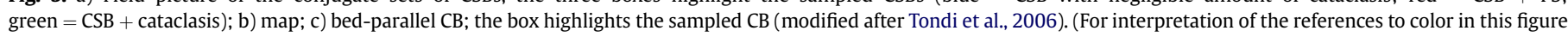
legend, the reader is referred to the web version of this article.)

Measurements were made in two orthogonal directions parallel and perpendicular to the inferred $\sigma_{1}$, respectively. We denoted the linear intercept density (number of pressure solution intersections per unit length) for the array oriented parallel to $\sigma_{1}$ by $P_{L}^{\|}$, and that for the perpendicular array by $P_{L}^{\perp}$. Following the method applied by $\mathrm{Wu}$ et al. (2000), we used the approximation of equation (1) to define the value of the pressure solutions anisotropy factor (Underwood, 1970):

$\Omega_{23}=\frac{P_{L}^{\perp}-P_{L}^{\|}}{P_{L}^{\perp}+(4 / \Pi-1) P_{L}^{\|}}$

The parameter $\Omega_{23}$ represents the ratio between the surface area of pressure solution parallel to $\sigma_{1}$ and the total pressure solution surface area. The results of the spatial distribution of PSs, relative to different stages of the deformation, are listed in Table 3. We highlighted the evolution of the anisotropy factor $\left(\Omega_{23}\right)$ in the different natural DBs. In the CSB with negligible amount of cataclasis, where intergranular PSs are randomly distributed at the grain contacts, we measured $\Omega_{23}=0.029$ that represents an isotropic distribution, whereas in the CSB with band-parallel PSs we measured $\Omega_{23}=0.2$, probably because the PSs follow the band orientation and form and angle of about $35^{\circ}$ with respect to the inferred $\sigma_{1}$. On the other hand, we found negative values (anisotropic but in the direction of $\left.\sigma_{3}\right)$ of $\Omega_{23}$ in both the CSB with cataclasis and the CB. In the first structure it is likely due to the presence of a second set of tail PSs localized in the contractional quadrants of the sheared PSs, whereas in the CB it is due to the parallel orientation of the PSs with respect to the band, which developed perpendicularly to the $\sigma_{1}$. Pressure solutions overprinting the bed-parallel CBs were not shown in Tondi et al. (2006), but have been documented on samples of the Oligo-Miocene Bolognano Formation by Agosta et al. (2009); Rustichelli et al. (2012).
Finally, we determined the degree of microtextural ordering inside and outside the CSB and the $\mathrm{CB}$, by studying the preferred orientation and trace of chains composed of grains, which are in concave-convex contact. These chains were obtained by connecting a minimum of three adjacent grains with concave-convex contacts. The chain trajectories were drawn perpendicular to the grain contacts, we refer to these trajectories as force chains (Potyondy and Cundall, 2004) and consider them a two-dimensional proxy for the orientation of the load-bearing framework in the threedimensional granular aggregate (Eichhubl et al., 2010). The force chains were drown on the thin section maps (Figs. $6 \mathrm{~b}$ and $7 \mathrm{~b}$ ), we then measured the angles formed by each chain and the vertical direction by considering 0 to $-90^{\circ}$ anticlockwise and $0-90^{\circ}$ the reverse (chain angles). We plotted all the angles using symmetric rose diagrams (Fig. 10), each petal of the diagrams covers $10^{\circ}$. The petals length provides information about the percentage of chain angles included in that range. In the host rock (Fig. 10a) the chain angles show two main orientation: $30-50^{\circ}$ and 0 to $-30^{\circ}$; whereas in the CSB Fig. 10b there is a preferential orientation of $0-20^{\circ}$, which is parallel to the maximum shortening direction. The host rock of Fig. 10c shows a pronounced angle iso-orientation $\left(-20-0^{\circ}\right)$, which is perpendicular to the bedding. Even if in the CB (Fig. 10d) the chains have a predominant vertical orientation, two other trends are also visible $\left(-40\right.$ to $-30^{\circ}$ and $\left.30^{\circ}\right)$.

\section{Laboratory deformation bands}

\subsection{Experimental procedures}

For the experimental part of the research we followed to two parallel strategies. Each strategy was performed in an individual laboratory. First a systematic investigation of the brittle-ductile transition of S18 Upper ("Majella grainstone" in Baud et al., 2009) was conducted at the Ecole et Observatoire des Sciences de la Terre 

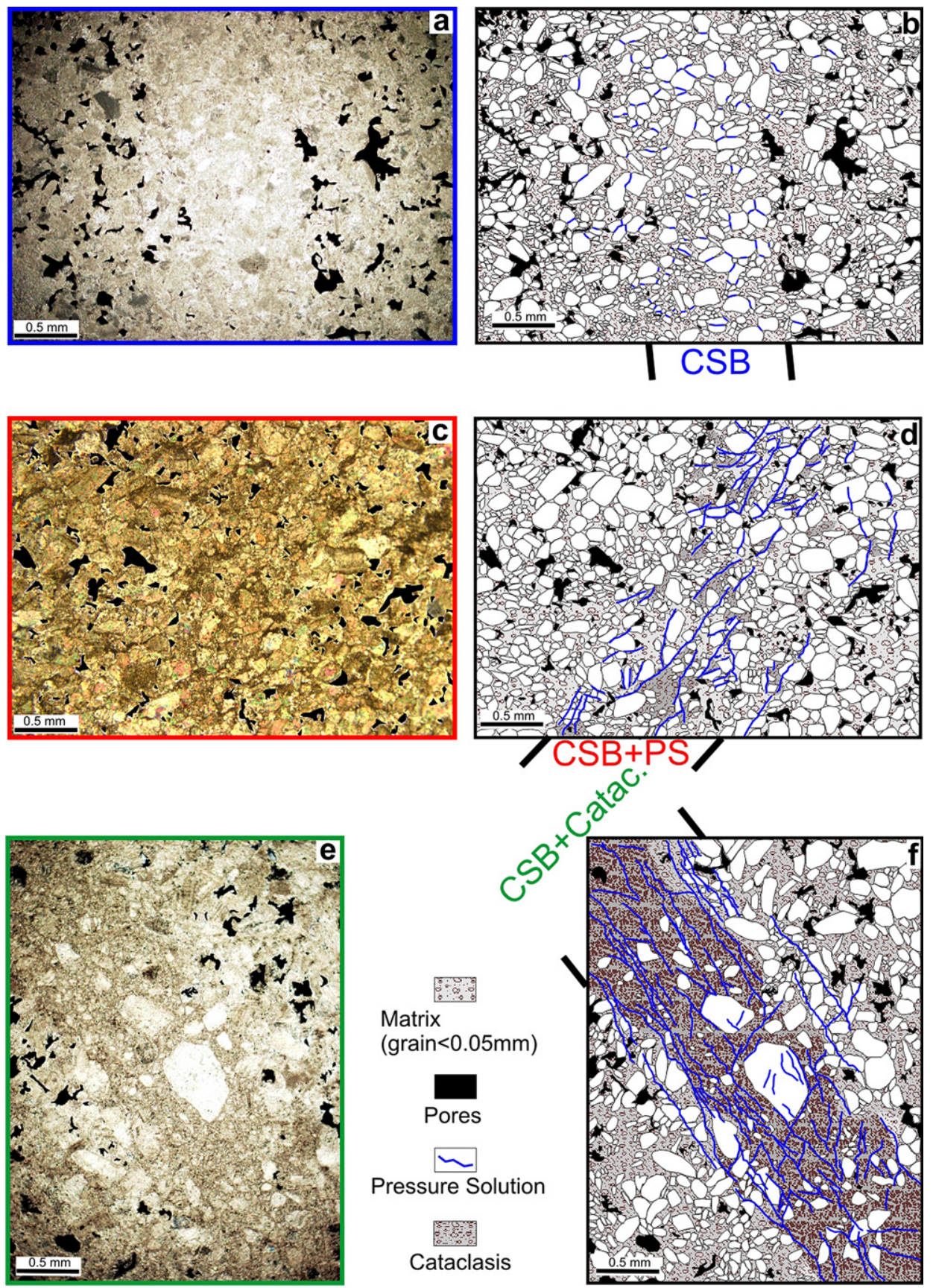

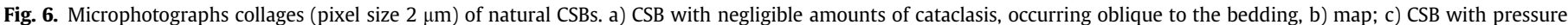
solutions and discontinuous pockets of cataclasis, d) map; e) CSB characterized by continuous tabular zone of cataclasis and f) map (modified after Tondi et al., 2006).

(EOST) in Strasbourg (Table 4). This study aimed at extending to wet conditions the work published by Baud et al. (2009) on dry Orfento grainstone. Second, based on EOST data, a few pilot experiments on different layers of the Orfento grainstones were performed at selected pressures and using different strain rates to tentatively assess the strain rate dependence of the different processes (Table 5). These last experiments were carried out on three layers (S11 Low., S18 Low. and S19) at the Utrecht University, Faculty of Geosciences, Department of Earth Sciences (HPT-Lab). In this part, we were limited by the small number of samples available, thus we could not repeat systematically the same experiments on all layers and we therefore did some exploratory work aiming at identifying various types of DB. After deforming the samples, microstructural analysis was however systematically carried out on all samples.

\subsubsection{EOST experimental procedure}

Cylindrical samples (20-mm of diameter and $40-\mathrm{mm}$ of length) were cored from same block of Orfento Formation ("Majella grainstone") used by Baud et al. (2009) and in the same orientation (see Fig. 2 and Table 1). Starting porosity was determined using two techniques: water saturation, and gas pycnometer (Accupyc 1330) (Baud et al., 2009). The cores were first wrapped in a $0.05 \mathrm{~mm}$-thick copper foil to avoid horizontal cracking during unloading, than jacketed by mean of a heat-shrinkable neoprene tube in order to be 


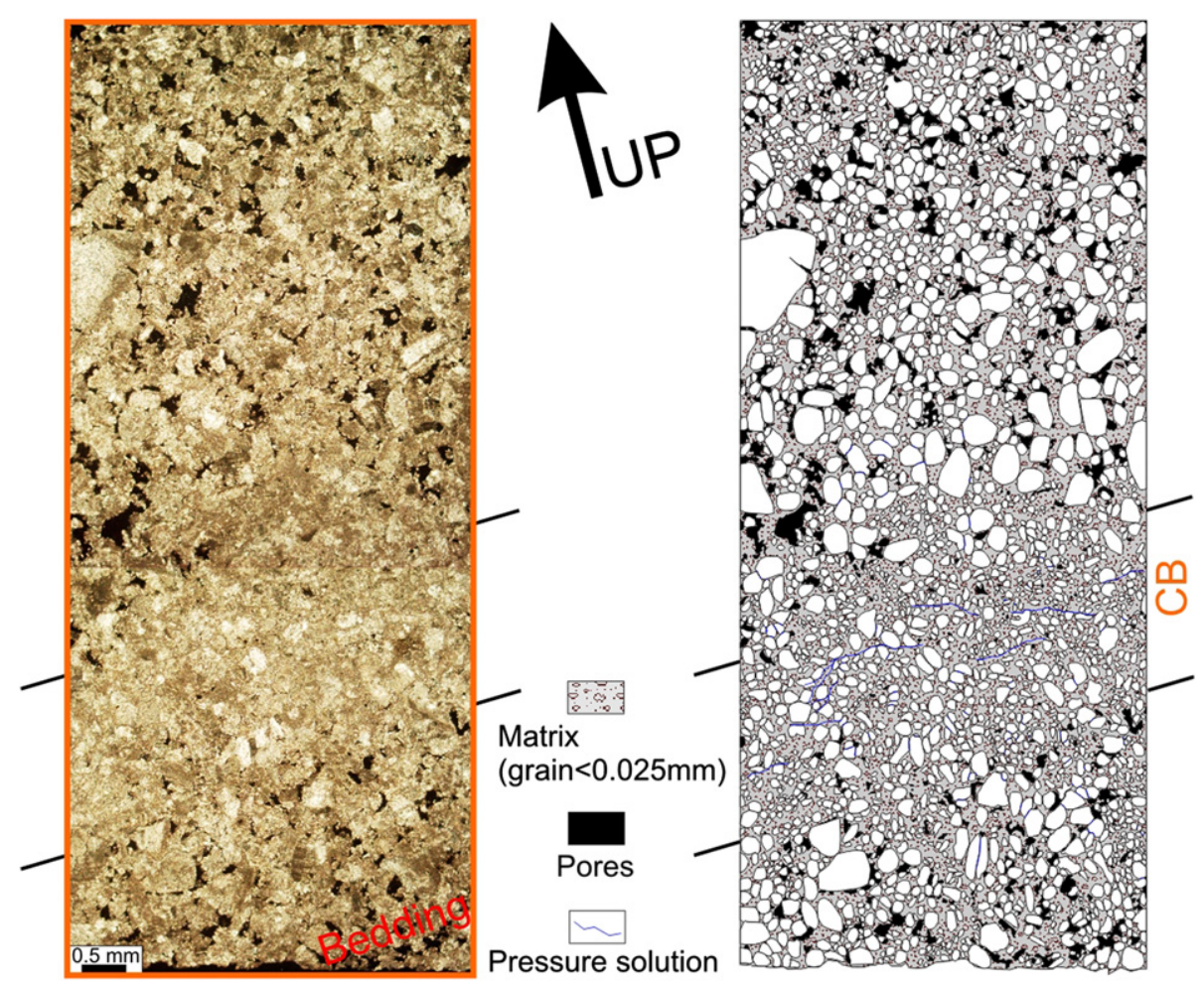

Fig. 7. Microphotographs collage (pixel size $2 \mu \mathrm{m}$ ). a) Bed-parallel CB overprinted by pressure solutions, b) Microphotographs map.

isolated from the confining medium. 10 specimens were deformed in conventional triaxial configuration at room temperature with effective confining pressures ranging from 5 to $20 \mathrm{MPa}$, see Baud et al. (2009) for apparatus and measurements details. The samples were saturated with deionized water and the pore pressure was kept constant at $10 \mathrm{MPa}$ under fully drained conditions. The pore volume change was recorded by monitoring the displacement of the pore pressure generator with an angular encoder, the porosity change was calculated from the ratio of the pore volume change to the initial bulk volume of the sample. A computer-controlled stepping motor, connected to a pressure transducer, regulated the confining pressure with an accuracy of $0.05 \mathrm{MPa}$. The axial load was applied by a piston controlled by a second computer-controlled stepping motor, axial displacement was measured outside the pressure vessel with a capacitive transducer with accuracy $0.2 \mu \mathrm{m}$ mounted on the moving piston and servo-controlled at a fixed rate (corresponding to a nominal strain rate of $10^{-5} \mathrm{~s}^{-1}$, Table 4).

\subsubsection{HPT lab experimental procedure}

Seven cylindrical samples (25-mm of diameter and 55-mm of length) were cored from 3 blocks of Orfento Formation (see Fig. 2 and Table 1, characterized by similar porosities but different grain sizes) perpendicularly with respect to bedding. Starting porosity was determined using two techniques: water saturation of the cores, and gas pycnometer (Accupyc 1330). The cores were jacketed by mean of a $0.9-\mathrm{mm}$ thick butyle tube in order to be isolated from the confining medium. The specimens were deformed in a selfcompensating volume triaxial deformation apparatus, at room temperature, with effective confining pressures ranging from 5 to $30 \mathrm{MPa}$ (Table 5). The samples were saturated with demineralized water and the pore pressure was held constant to within $0.01 \mathrm{MPa}$ of a desired value ( $8 \mathrm{MPa}$ in the present experiments) using a threeterm (PID) electro-servo mechanical pump. Axial force on the sample was measured using a Differential Variable Reluctance Transducer (DVRT) located in the loading piston near the bottom of the pressure vessel. The DVRT used has a full-scale of $100 \mathrm{kN}$, along with a $\pm 35 \mathrm{~N}$ resolution. The change in pore volume of the sample assembly was monitored by recording the volume of the servomechanical pump. We used these data to determine the porosity change of the sample (i.e. by calculating the ratio of the pore volume change to the initial bulk volume of the sample). Axial displacement was measured using a Linear Variable Differential Transducer (LVDT) attached outside the pressure vessel to the electro-servo controlled ram for axial loading. Two sets of experiments were performed using nominal strain rates of $10^{-5} \mathrm{~s}^{-1}$ and $10^{-7} \mathrm{~s}^{-1}$ respectively, this allowed us to investigate the possible influence of strain rate on the micromechanisms occurring within the of DBs.

Table 2

Summary of the rock components (2D measurements): pores (not comprehensive of micropores $<10 \mu \mathrm{m}$ ), grains and matrix.

\begin{tabular}{|c|c|c|c|c|c|c|c|c|}
\hline \multirow[t]{2}{*}{ Rock component [\%] } & \multicolumn{2}{|l|}{ CSB } & \multicolumn{2}{|l|}{$\mathrm{CSB}+\mathrm{PS}$} & \multicolumn{2}{|c|}{ CSB + Cataclasis } & \multicolumn{2}{|l|}{$\mathrm{CB}$} \\
\hline & Surr. HR & Band & Surr. HR & Band & Surr. HR & Band & Surr. HR & Band \\
\hline Grain & 43.7 & 52.24 & 47.7 & 43 & 43 & 15.7 & 46.4 & 67.3 \\
\hline Pore & 9.7 & 0.53 & 6.7 & 4 & 8.1 & 0.31 & 12.6 & 0.7 \\
\hline Matrix & 26.4 & 25.4 & 23.56 & 35.8 & 40 & 65 & 41.1 & 32.1 \\
\hline Grain/Matrix & 1.65 & 2.06 & 2.025 & 1.20 & 1.08 & 0.24 & 0.89 & 0.48 \\
\hline
\end{tabular}




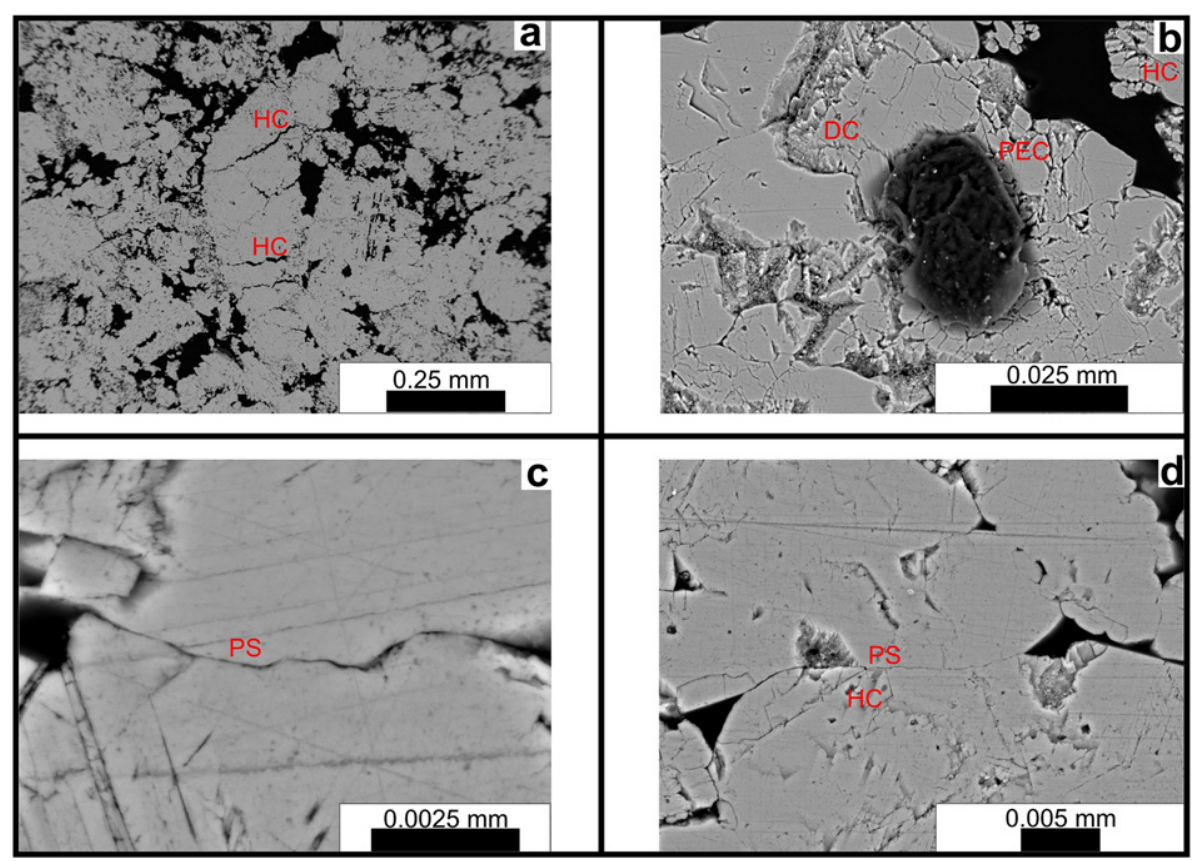

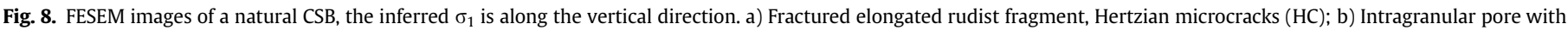
pore-emanated cracks (PEC) and dissolution channels (DC); c) Pressure solution (PS) at the grain contacts; d) Pressure solution at the grain contacts and Hertzian cracks.

\subsection{Mechanical data}

In the following section, we consider the compressive stresses and compactive strains (i.e. shortening and porosity decrease) as positive. The maximum and minimum (compressive) principal stress axes are denoted by $\sigma_{1}$ and $\sigma_{3}$, respectively, whereas the pore pressure is reported as $P_{p}$. The difference between the confining pressure $\left(P_{c}=\sigma_{2}=\sigma_{3}\right)$ and pore pressure is referred as the effective pressure $\left(P_{\text {eff. }}\right)$. Moreover, the effective mean stress $\left(\left(\sigma_{1}+2 \sigma_{3}\right) /\right.$ 3) $-P_{p}$ and the differential stress $\sigma_{1}-\sigma_{3}$ are denoted by $P$ and $Q$, respectively. We define brittle failure a mode in which in a stressstrain curve strain softening is recorded beyond reaching a peak stress, while ductile a failure mode in which a stress-strain curve displays strain hardening after a yield point.

Baud et al. (2009) published data on a wet hydrostatic compaction experiment carried out on a sample of the Orfento Formation (dashed line Fig. 11b). The aforementioned authors observed two trends associated to two different stages of deformation: i) an approximately linear poroelastic stage at low pressure, which indicates that no significant crack porosity is present; and ii) a second stage showing deviation from linearity, corresponding to the onset inelastic deformation (grain crushing and pore collapse). The effective pressure at the transition is denoted $P^{*}$, which corresponds to an inflexion point (26.5 MPa) in the hydrostatic curve. Moreover, by comparing the wet hydrostatic experiment with the dry one, Baud et al. (2009) showed a significant weakening effect of water in Orfento grainstone.

\subsubsection{EOST experiments}

Mechanical data relative to selected experiments (Table 4) are shown in Fig. 11. The differential stress as a function of axial strain is shown in Fig. 11a, while, in Fig. 11b, we show the porosity reduction as the function of the effective mean stress.

The experiments performed at $5 \mathrm{MPa}$ of $\mathrm{P}_{\text {eff }}$, showed a typical a brittle behavior for which the stress-strain curves reached a peak beyond which strain softening followed. Several experiments were repeated at this effective pressure. While the peak stress was quasi- constant in all tests, we observed some variability in the post-peak behavior, stress drops ranging from 2 to $5 \mathrm{MPa}$. Beyond $10 \mathrm{MPa}$ of effective pressure strain hardening was always observed in the ductile regime.

In wet conditions, the mechanical behavior of these Orfento samples was always compactant, as previously observed in dry conditions (Baud et al., 2009; Zhu et al., 2010). Wong et al. (1997) showed that the hydrostatic and non-hydrostatic loadings are coupled in a triaxial compression experiment. In the compactive regime, they identified the yield point as the critical pressure $C^{*}$, at which the deviatoric part of the loading resulted in an acceleration of the compaction with respect to the hydrostatic behavior. This phenomenon of shear-enhanced compaction (Curran and Carroll, 1979) was observed in all the performed experiments (Fig. 11b).

\subsubsection{HPT-lab experiments}

The mechanical data relative to seven experiments are shown in Fig. 12. Since this study mainly focused on the development of compactive shear bands, we decided to perform most of the seven

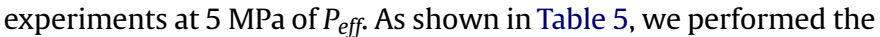
experiments at two different strain rates of $10^{-5} \mathrm{~s}^{-1}$ and $10^{-7} \mathrm{~s}^{-1}$ (Table 5).

For these experiments we used three different blocks of the Orfento formation (Fig. 2 and Table 5). Accordingly, we plot the experimental data in different graphs related to the individual blocks. We show the differential stress as a function of axial strain curves for samples S11 Low., S18 Low. and S19 in Fig. 12a, c, e. In Fig. 12b, d, f we show the porosity reductions as a function of axial strain, moreover the Fig. $12 \mathrm{~g}$ shows the mean stress versus porosity reduction of the experiment T1. Samples S11 Low and S18 Low depicted a compactant behavior in all the experiments (T1; T2; T10 and T12), while in the three tests carried out on sample S19 (T7; T11; T14) we observed evidence of dilatancy. By comparing the results (Fig. 12) of the experiments T12 (S18 Low.) with T7, T11 and T14 (S19) it comes out that, at the same strain rate $\left(10^{-7} \mathrm{~s}^{-1}\right)$, siltgrained grainstone are stronger than very fine sand to silt-grained grainstone, which suggests that grain size might be negatively 
Pore size distributions
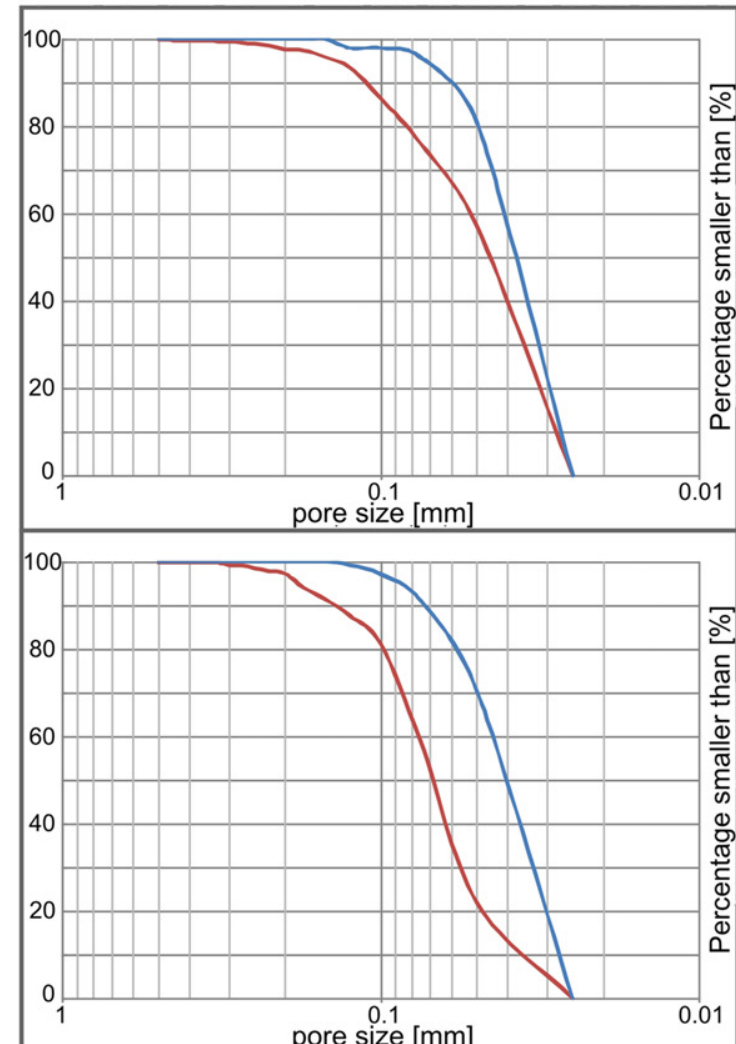

100 100
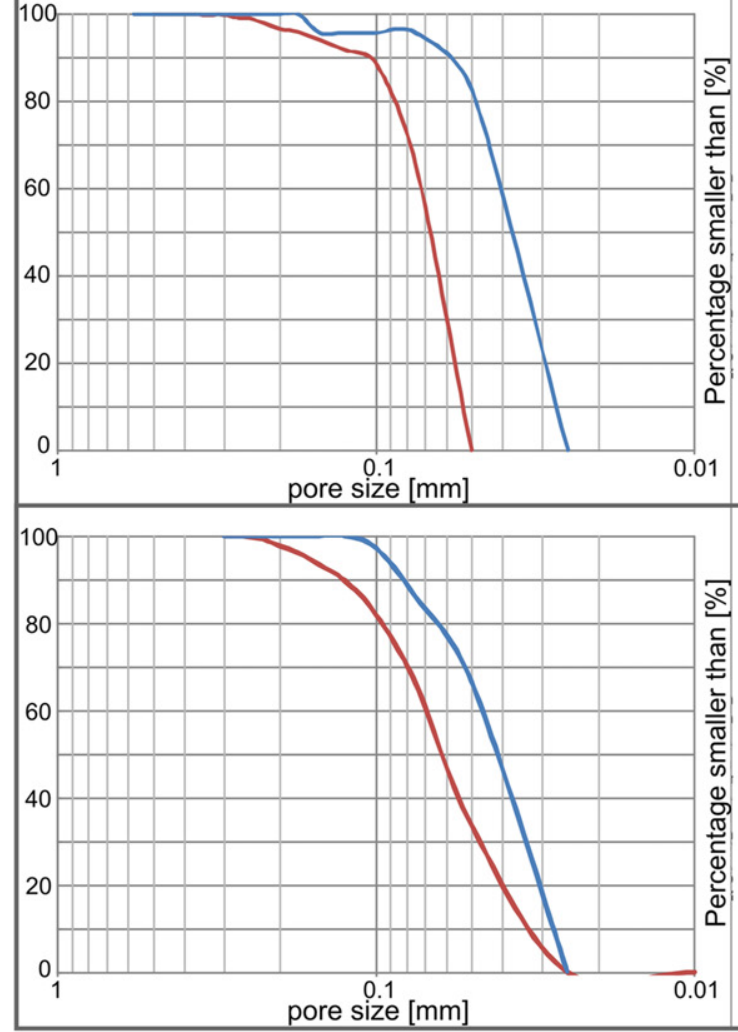

Grain size distributions

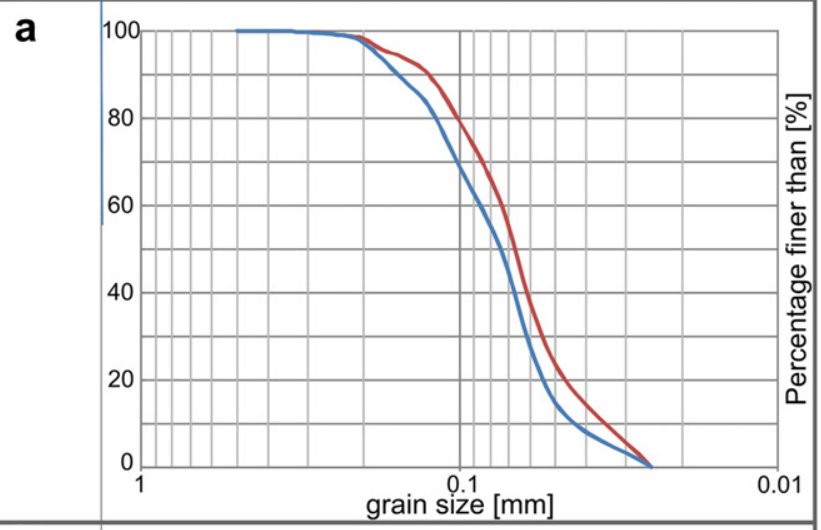

b

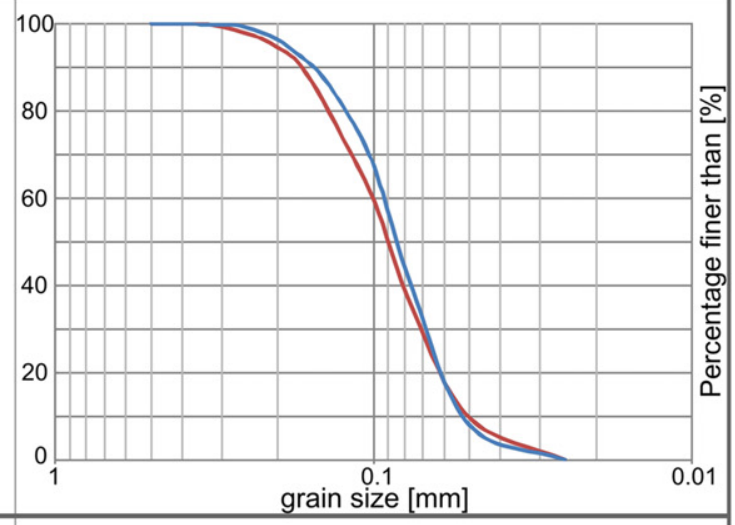

C

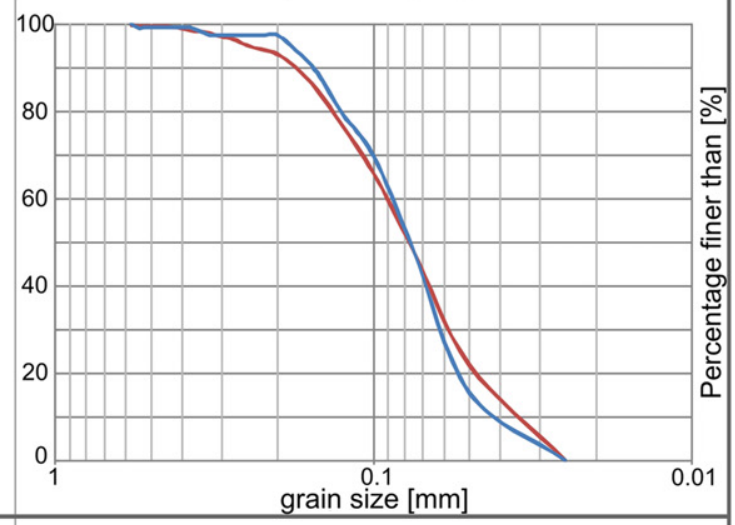

d

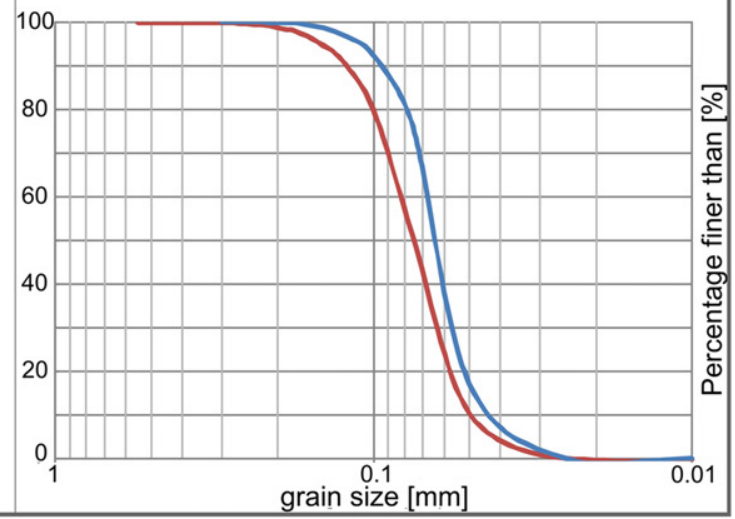

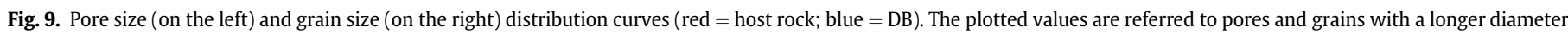

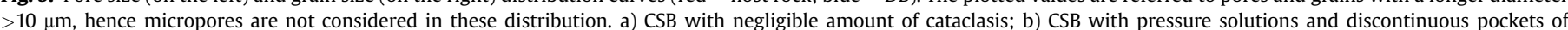

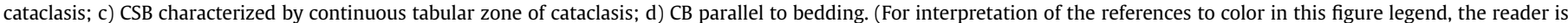
referred to the web version of this article.) 
Table 3

Values calculated for natural DBs by means of stereological technique.

\begin{tabular}{lccc}
\hline Sample & $\begin{array}{l}\text { PS for linear intercepts } \\
\text { perpendicular to } \sigma_{1} \\
{\left[\mathrm{~mm}^{-1}\right]}\end{array}$ & $\begin{array}{l}\text { PS for linear intercepts } \\
\text { parallel to } \sigma_{1}\left[\mathrm{~mm}^{-1}\right]\end{array}$ & $\begin{array}{l}\text { Anisotropy } \\
\text { factor } \Omega_{23}\end{array}$ \\
\hline CSB & $2.807 \pm 2.3$ & $2.91 \pm 1.63$ & 0.029 \\
CSB + PS & $4.6 \pm 2.1$ & $6.1 \pm 7.1$ & 0.20 \\
CSB + Catac. & $1.9 \pm 1.91$ & $1.2 \pm 1.08$ & -0.39 \\
CB & $1 \pm 0.75$ & $0.51 \pm 0.31$ & -0.63 \\
\hline
\end{tabular}

related to the strength of these carbonates, in agreement with Baud et al. (2009) and previous data on porous sandstone (Wong and Baud, 1999).

All the experiments carried out at $5 \mathrm{MPa}$ of $P_{\text {eff, showed a brittle }}$ behavior with post-peak stress drops ranging between 1 and $4 \mathrm{MPa}$. In the experiments carried out $P_{\text {eff: }}: 24$ and $30 \mathrm{MPa}$, significant strain hardening was observed beyond the onset of shearenhanced compaction (Fig. 12).

In Fig. 13 we compiled our data in the stress space (Effective mean stress vs Differential stress) in order to compare them with the dry ones published by Baud et al. (2009). The comparison of the yield points highlights furthermore the weakening effect of water on the strength of the Orfento grainstones. Moreover, by comparing the wet experiments performed at $5 \mathrm{MPa} \mathrm{P}_{\text {eff }}$ (lying on the dashed line, Fig. 13) the influence of both porosity and grain size on the rock strength is visible (in agreement with Baud et al., 2009 and Zhu et al., 2010). In fact coarser and more porous samples are also the weakest (Fig. 13). If we compare the peak stresses of the experiments: Orfento \#3 (layer S11 Upp.) and T1 (layer S11 Low, this layer is coarser but $1 \%$ less porous than S11 Upp.) we notice that T1 has a higher peak than Orfento \#3. Since both grain size and porosity are negatively related to strength (i.e. Baud et al., 2009) a morepronounced effect of porosity than grain size can be inferred.

\subsection{Sample analyses}

Selected samples deformed at different level of axial strain were unloaded and retrieved from the pressure vessels. The deformed samples were carefully removed from the jacket (neoprene or butyle) then macroscopically analyzed in order to identify some possible strain localization zones. As examples of the work done, we present three pictures of deformed samples from the HPT-lab experiments (Fig. 14). From a macroscopic point of view, strain localization occurred along DBs, which are lighter-colored, and appear more compact with respect to the other portions of the specimens. These DBs present a powdery texture due to the localized cohesion loss among the grains (Fig. 14). The angles formed by these structures with respect to the $\sigma_{1}$ axis vary between $20^{\circ}$ and $45^{\circ}$ for the experiments at $5 \mathrm{MPa}$ of $P_{\text {eff }}$ (Fig. 14, T1 and T11) and between $74^{\circ}$ and almost $90^{\circ}$ for the two experiments at 30 and $24 \mathrm{MPa}$ of $P_{\text {eff }}$ respectively (Fig. $14 \mathrm{~T} 2$ and Fig. 16b). In the experiments T1 and T11 ( $\left.P_{\text {eff. }}=5 \mathrm{MPa}\right)$ we observed conjugate CSBs, the angle between the CSBs ranges between $40^{\circ}$ in $\mathrm{T} 11$ and $90^{\circ}$ in $\mathrm{T} 1$.

Table 4

Summary of EOST experiments.

\begin{tabular}{lllll}
\hline Sample Code & $\begin{array}{l}\text { Experiment } \\
\text { Code }\end{array}$ & $\begin{array}{l}\text { Porosity } \\
{[\%]}\end{array}$ & $\begin{array}{l}\text { Eff. confining } \\
\text { pressure [MPa] }\end{array}$ & $\begin{array}{l}\text { Axial strain } \\
{[\%]}\end{array}$ \\
\hline S18 Upp. & Ma\#13 & 30 & 16 & 3 \\
S18 Upp. & Ma\#14 & 30 & 10 & 1.6 \\
S18 Upp. & Ma\#15 & 30 & 19 & 4 \\
S18 Upp. & Ma\#33 & 30 & 20 & 3.2 \\
S18 Upp. & Ma\#34 & 30 & 5 & 0.65 \\
S11 Upp. & Orfento \#3 & 32 & 5 & 0.7 \\
\hline
\end{tabular}

\subsection{Microstrutural observations}

We vacuum impregnated the samples with epoxy resin and sawed them along a plane parallel to the axial direction to prepare petrographic thin sections. The thin sections were subsequently polished for using FESEM and optical polarizing microscope (Nikon Eclipse E600 Pol microscope). The analyses of the textural parameters, as well as the micromechanical characterization of the laboratory DBs, were carried out following a procedure similar to that one described for natural DBs. In addition, for laboratory DBs, we calculated the crack surface area per unit volume $\left(S_{V}\right)$. Previous studies (Wu et al., 2000 and references therein) have demonstrated that since the spatial distribution of damage is approximately axisymmetric in a triaxially deformed sample, $S_{V}$ can be inferred from linear intercept measurements along two orthogonal directions, see equation (2):

$S_{v}=\frac{\Pi}{2} P_{L}^{\perp}+\left(2-\frac{\Pi}{2}\right) P_{L}^{\|}$

The mechanical data of the deformed carbonate grainstones (Section 4.1) suggest that shear-enhanced compaction is followed by the three main failure modes: shear failure, compaction localization and cataclastic flow. In this section, we present the results relative to five selected microstructures: two low-angle to $\sigma_{1}$ CSBs and three high-angle to $\sigma_{1}$ DBs. The studied specimens (i.e. Ma\#34; Orfento\#3; T1; T2; T10) represent different stages of deformation, from 0.65 to $4.5 \%$ of axial strain (Tables 4and 5). Independently from the grain size of the undeformed host rock, all the analyzed DBs are thinner than $0.5 \mathrm{~mm}$, indeed the thickest one $(0.5 \mathrm{~mm})$ is the Ma\#34, which formed in the finest of the deformed lithofacies. The porosities of inner portions of the laboratory DBs, measured in thin section, are lower than the surrounding host rock (between 3.3 and $8.2 \%$; Table 6; values not comprising of pores with the major diameter $<10 \mu \mathrm{m}$ ). The observed porosity reduction, which in $2 \mathrm{D}$ represents around the $75 \%$ of the original host rock values, is consistent with the CSBs documented in dry experiments by Baud et al. (2009). The deformation bands formed during T1 and T2 experiments (both from sample S11), are alternating fine powder layers sub-parallel to the band orientation and heterogeneously cracked grains (Figs. 15b and 16a). These bands appear similar to those previously documented by Baud et al. (2009) in dry experiments. Differently, the other bands that nucleated in the samples: S11 Upp., S18 Upp. and S18 Low. show a more chaotic texture, clear evidence of particulate flow and significant comminution are detectable (Fig. 15a, c, d and Fig. 16b). The grain-to-matrix ratio of these latter DBs (calculated on photographs with pixel sizes ranging from 0.5 to $2 \mu \mathrm{m}$ ) is lower than in the bands T1 and T2 (Table 6). The laboratory DB nucleated at $P_{\text {eff }}=24 \mathrm{MPa}$ during the experiments T10 is oriented perpendicular to $\sigma_{1}$ (Fig. 15b). In thin section it appears continuous and shows pore and grain sizes reduction in its internal portion (Fig. 15b FESEM magnifications). We observed similar zones of localized grain and pore size reduction in the experiment Ma\#33 too (Fig. 18f), but in that sample they only represent few discontinuous patches.

The pore and grain sizes distribution curves relative to the CSB Ma\#34 (Fig. 17) were calculated by using a combination of both optical and FESEM images because optical microphotographs alone were not able to describe the grain size and pore size reduction within the band. Indeed for the host rock the pore size $\mathrm{D}_{50}=4.5 \mu \mathrm{m}$, in the damage zone $=6.5 \mu \mathrm{m}$ and in the CSB $=3 \mu \mathrm{m}$. The grain size, on the other hand is $9.5 \mu \mathrm{m}$ in the host rock, $4.5 \mu \mathrm{m}$ in the damage zone and $3.5 \mu \mathrm{m}$ in the CSB.

The spatial distribution of cracks was investigated within three different structures (Ma\#34, T1 and T10). The measured values, listed in Table 7, allow us to highlight the evolution of the both 


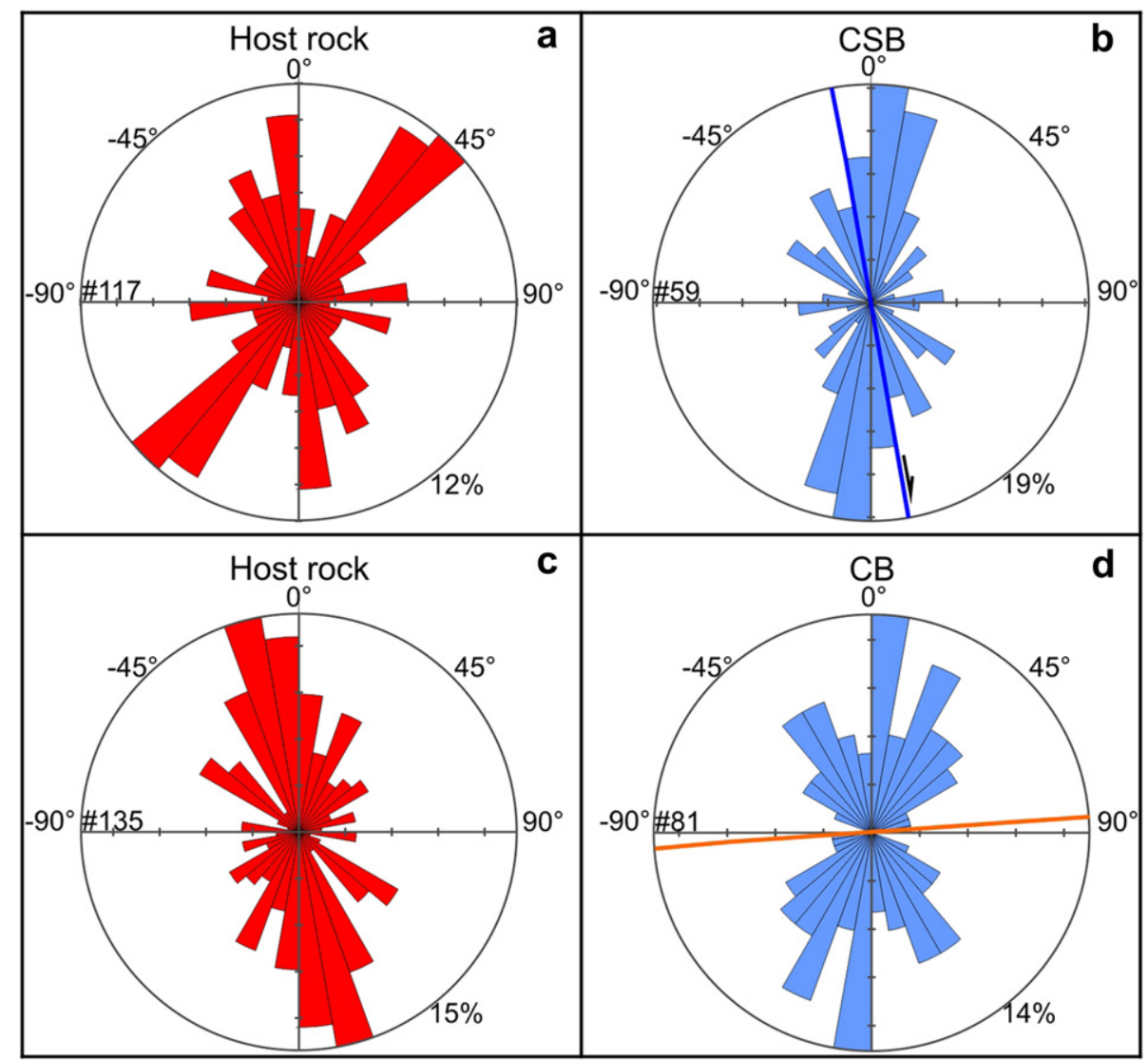

Fig. 10. Symmetric rose diagrams showing the orientation of the force chains. a) and c) host rocks, b) CSB and d) CB.

anisotropy factor $\left(\Omega_{23}\right)$ and crack area per unit of volume $\left(S_{v}\right)$. In both the CSBs Ma\#34 and T1 the $S_{v}$ increases significantly from the host rock to the band, $\Omega_{23}$ is almost zero in the experiment Ma\#34 both inside and outside the CSB, whereas in T1, it is zero in the host rock and 0.39 in the CSB. The CB of experiment T10 is more damaged than the host rock, while the $\Omega_{23}$ values show anisotropy within the band and isotropy in the host rock.

\subsubsection{Micromechanisms}

The microstructural analysis we performed allows us to define grain crushing as the dominant deformation microprocess within the laboratory DBs. As shown in Fig. 18, at low confining pressures, the cracks form either at the grain contacts (Hertzian cracks, Zhang et al., 1990; Brzesowsky et al., 2011) or, alternatively, in the proximity of slip surface (Wing cracks, Ashby and Sammis, 1990). These two typologies of cracks are characterized by different preferential orientation of propagation with respected to $\sigma_{1}$. Thus, Hertzian cracks are almost randomly oriented within the CSBs and in less amount they are present also outside the CSBs, whereas wing

Table 5

Summary of HPT-lab experiments.

\begin{tabular}{lllcll}
\hline Sample code & $\begin{array}{l}\text { Experiment } \\
\text { code }\end{array}$ & $\begin{array}{l}\text { Porosity } \\
{[\%]}\end{array}$ & $\begin{array}{l}\text { Eff. confining } \\
\text { pressure [MPa] }\end{array}$ & $\begin{array}{l}\text { Axial } \\
\text { strain [\%] }\end{array}$ & $\begin{array}{l}\text { Strain rate } \\
{\left[\mathrm{s}^{-1}\right]}\end{array}$ \\
\hline S11 Low & T1 & 31 & 5 & 3.5 & $10^{-5}$ \\
S11 Low & T2 & 31 & 30 & 4.5 & $10^{-5}$ \\
S19 & T7 & 30.15 & 5 & 0.65 & $10^{-7}$ \\
S18 Low & T10 & 31.89 & 24 & 0.9 & $10^{-7}$ \\
S19 & T11 & 30.15 & 5 & 0.52 & $10^{-7}$ \\
S18 Low & T12 & 31.89 & 5 & 0.9 & $10^{-7}$ \\
S19 & T14 & 30.15 & 5 & 0.65 & $10^{-7}$ \\
\hline
\end{tabular}

cracks tend to propagate parallel to the local $\sigma_{1}$ direction and cluster in the extensional quadrants of the CSBs. At the higher confining pressures (beyond $10 \mathrm{MPa}$ ), grain crushing due to Hertzian cracks are generally diffuse in the samples, even if we documented examples of localization of this process (Fig. 19) in the experiments Ma\#33 (S18 Upper) and T10 (S18 Lower) characterized by grain sizes of 50 and $80 \mu \mathrm{m}$, respectively. In every analyzed sample, we observed indentations between neighboring grains. This phenomenon likely occurred because water better transported the comminuted material, formed at the grain contacts, enhancing the grain rearrangement (Figs. $18 \mathrm{~b}$ and 19e).

In the deformation of these carbonates, another important role is played by intergranular pores size reduction, which can be either due to the infilling of fine-grained material or to their cataclastic collapse. At low confining pressures, within the CSBs, the intergranular pores are obliterated by shear surfaces and/or filled by fine-grained material product by grain crushing and sliding (Fig. 18d). On the contrary, at the highest confining pressures, intergranular pores tend to collapse by elongating themselves in the direction parallel to $\sigma_{3}$ (Fig. 19b). Along the collapsed pore boundaries, we document damaged grains (in agreement with Vajdova et al., 2010, in press). Intragranular pores appear stiffer than the intergranular ones and less prone to collapse or be filled by fine-grained material. On these regards, in inner parts of two CSBs (i.e. Orfento\#3 and Ma\#34), we note some residual intragranular pores (Fig. 15a-c). Since equant pores act as stress concentrators, pore-emanating cracks can start departing from the residual intragranular pores present within the CSBs, similar observations have been provided by Vajdova et al. (2004) and (2010) and Zhu et al. (2010). We documented pore-emanating cracks in both low and high confining pressure experiments (Figs. 18f and 19d), but 

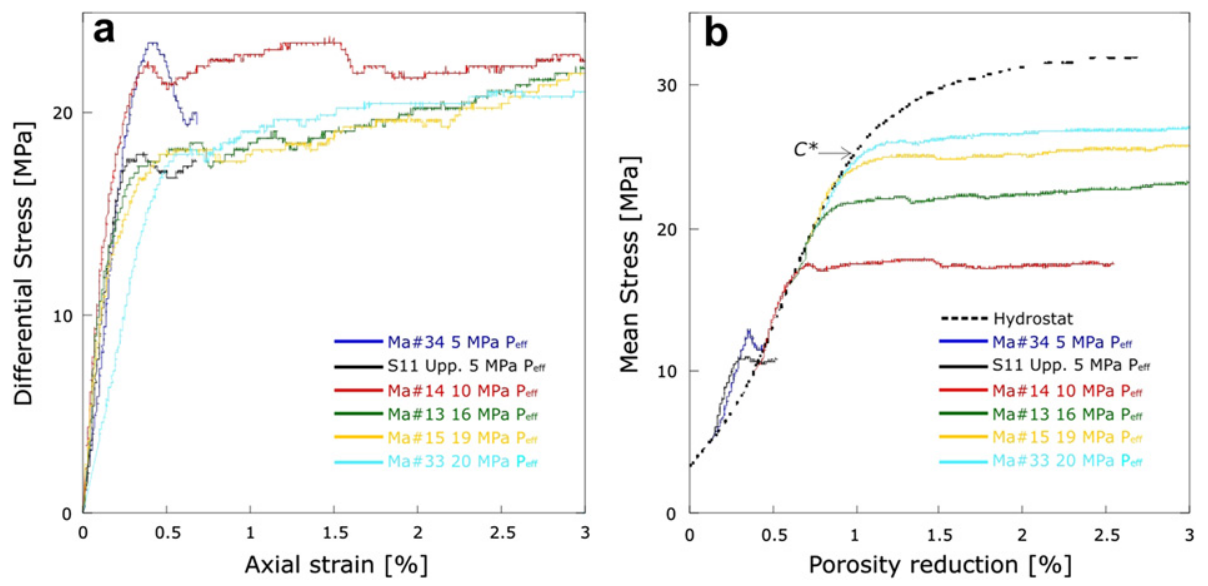

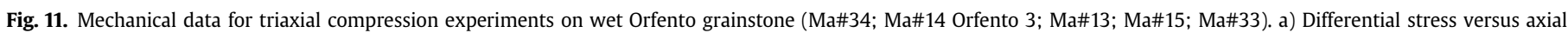
strain for experiments at confining pressures. b) Mean stress versus volumetric strain, with the dashed line the hydrostatic experiment from Baud et al. (2009).

while in the low-pressure experiment they were concentrated within the CSB, in the high pressure experiments these cracks were diffused in the whole sample. Calcite mechanical twinning (Fig. 18a) activity was not particularly developed in the deformed samples. In agreement with previous experimental works on carbonates (e.g. Baud et al., 2009; Vajdova et al., 2010, in press), we observed twinned calcite grains at every confining pressure. Indeed, by comparing the thin section observation, of two samples deformed at various confining pressures but at similar axial strains (i.e. T1 and Ma\#33), we highlight that the number of twinned grains seems to be positively correlated with the increasing of the confining pressure (Figs. 18c and 19c; in agreement with Vajdova et al., 2010, in press).

\section{Discussion}

We integrated field and laboratory observations carried out on natural and laboratory deformation bands formed in the grainstones of the Orfento formation. In order to constrain the pressure conditions at which natural deformation bands nucleate and to investigate the micromechanisms responsible of their formation, we carried out two sets of triaxial compression experiments. The
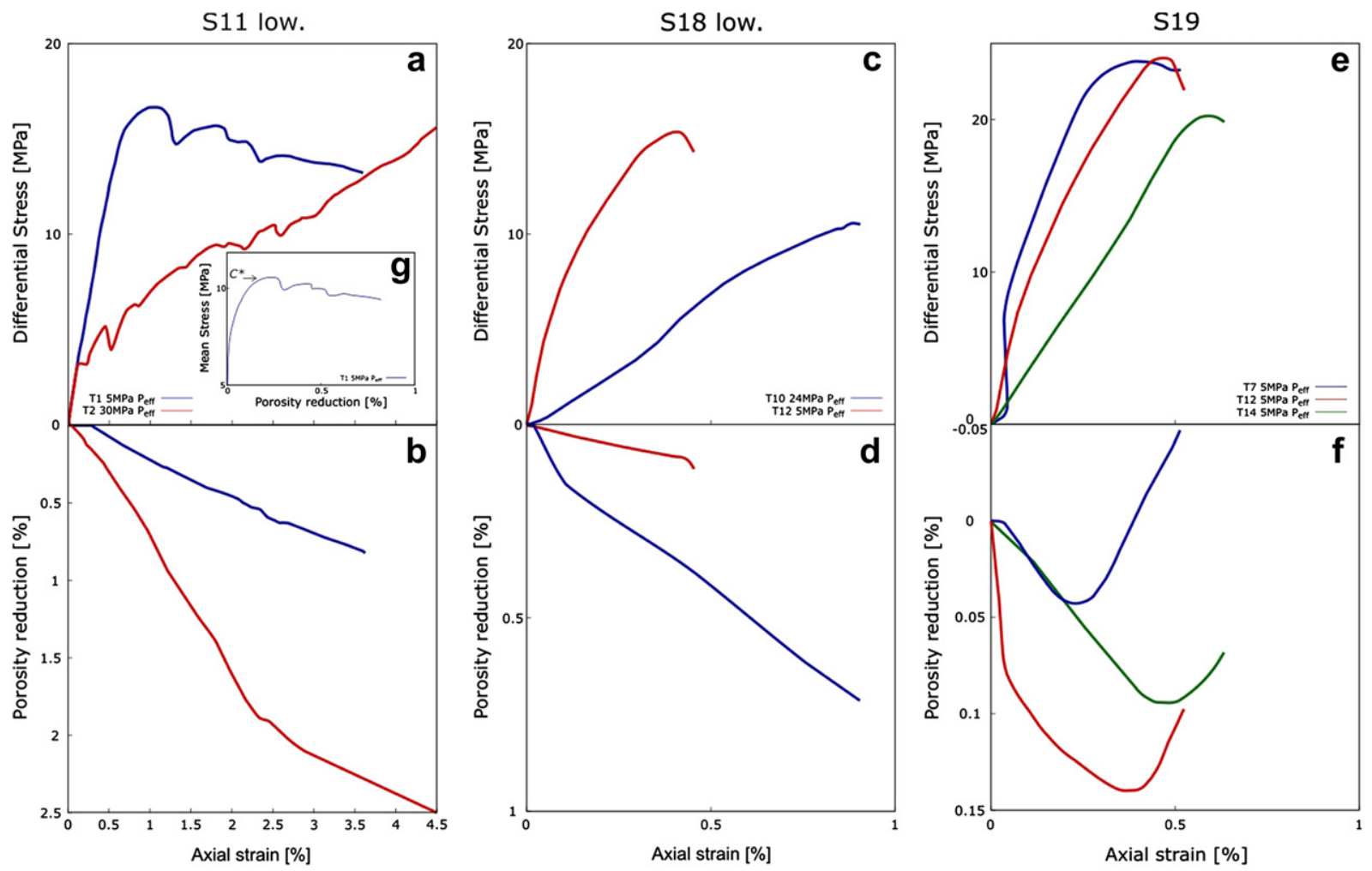

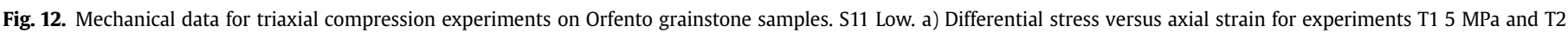

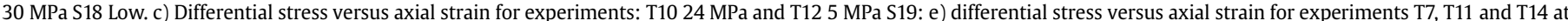

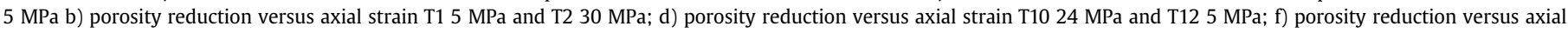
strainT7, T11 and T14 at 5 MPa. g) Mean stress versus axial strain for the experiment T1, which shows how the $\mathrm{C}^{*}$ was picked. 


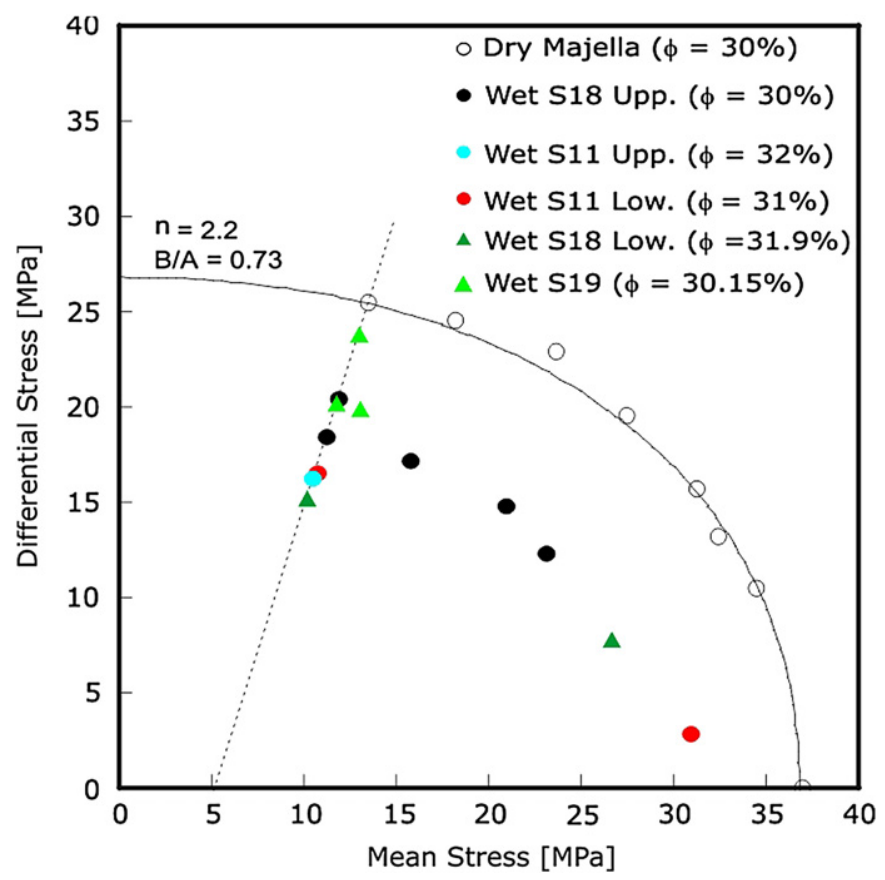

Fig. 13. Yield points of wet (this study) and dry (Baud et al., 2009) experiments on Orfento formation.

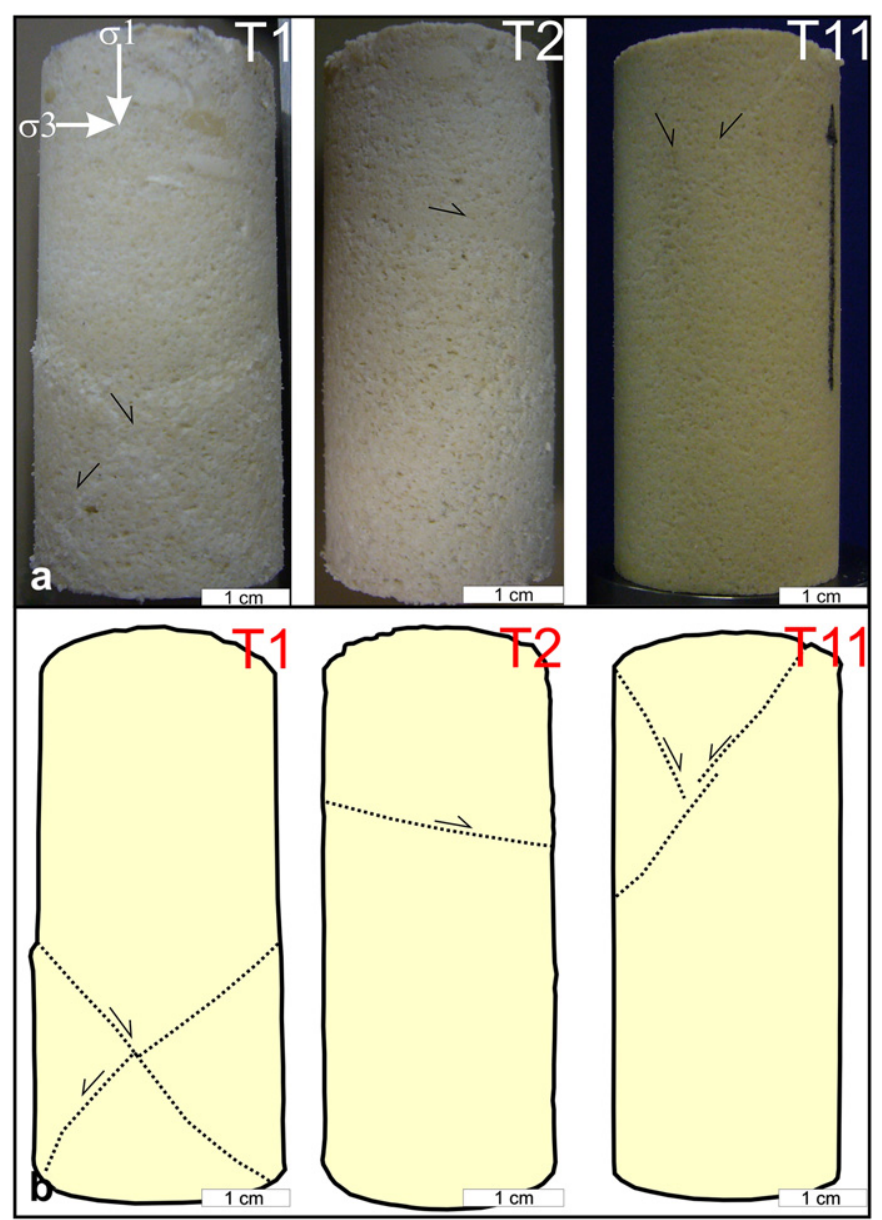

Fig. 14. Three deformed samples from HPT-lab; a) pictures CSBs in $\mathrm{T} 1$ and $\mathrm{T} 11$ and DB in $\mathrm{T} 2$. b) corresponding interpretation. experiments were performed at room temperature under wet conditions and at effective confining pressures ranging from 5 to $30 \mathrm{MPa}$.

At $5 \mathrm{MPa}$ of $\mathrm{P}_{\text {eff }}$ (Figs. 11 and 12) the deformed samples showed a brittle behavior, the peak stresses were quasi-constant in all tests. Some variability was shown in the post-peak behavior with stress drops ranging from 2 to $5 \mathrm{MPa}$. Differently from Baud et al. (2009), who documented brittle behavior up to $10 \mathrm{MPa}$ of confining pressure, in this work, under wet conditions, ductile failure was observed already at $10 \mathrm{MPa} P_{\text {eff.. }}$ These data are consistent with water having an important weakening role in these carbonates and lowering the brittle-ductile transition. Generally, a temperature increase promotes ductility and increases the strain rate sensitivity of carbonates (Paterson and Wong, 2004). On the other hand, Croizé et al. (2010a) demonstrated that a temperature up to $70{ }^{\circ} \mathrm{C}$ (corresponding to a depth $>2 \mathrm{~km}$, under a normal geothermal gradient $25^{\circ} \mathrm{C} / \mathrm{km}$ ) does not affect the mechanical compaction of bioclastic carbonate sand. Based upon these data, we consider that our room-temperature mechanical data represent a valid proxy for a variety of natural conditions. For all the wet experiments we observed a shear-enhanced compaction behavior in agreement with the dry data shown by Baud et al. (2009) and Zhu et al. (2010), with the exception of the experiment carried out on the sample S19, that documented a slight dilation.

Importantly both low- and high-angle to $\sigma_{1}$ structures were reproduced and compared to natural compactive shear bands and compaction bands. The aforementioned features will be discussed separately in the following sub-sections.

\subsection{Compactive shear bands}

Both natural and laboratory structures are lighter-colored and more compact with respect to the parent rock (Figs. 5 and 13). While the laboratory show to be poorly cohesive, the natural ones are even more lithified than the surrounding host rock (e.g. Tondi et al., 2006, 2012; Tondi, 2007; Rustichelli et al., 2012). This is a first macroscopic evidence of the different processes acting within the two typologies of DBs.

Previous field-based studies evidences that Orfento Fm. suffered a maximum overburden ranging between 0.7 and $1.3 \mathrm{~km}$ (e.g. Mutti et al., 1996). Based upon the failure modes and the similar angles among the laboratory low-angle to $\sigma_{1}$ CSBs (nucleated at $5 \mathrm{MPa}$ of $P_{\text {eff. }}$ ) and the natural CSBs, we infer that the natural structures developed at a depth shallower than $0.5 \mathrm{~km}(\approx 10 \mathrm{MPa})$.

The laboratory CBSs (nucleated at $P_{e f f}=5 \mathrm{MPa}$ ) form with $\sigma_{1}$ axis angles ranging between 30 and $40^{\circ}$, whereas the angle formed by the DB (Ma\#34; also at $P_{\text {eff }}=5 \mathrm{MPa}$ ) and the $\sigma_{1}$ axis is around $80^{\circ}$. Since the DB (Ma\#34) angle was measured in thin section, the discrepancy among the angles could be due to an inappropriate direction of the thin section cutting (not crossing perpendicularly the CSB). In two of the experiments performed at $P_{\text {eff }}=5 \mathrm{MPa}$, conjugate structures nucleated forming angles ranging between $40^{\circ}$ (T11) and $90^{\circ}$ (T1). Both specimens were characterized by similar porosity values ( 31 and 30.15 , respectively) and the only differences between them were the grain sizes (S11 Low coarser than S19; see Table 1$)$ and the strain rate $\left(T 1=10^{-5} \mathrm{~s}^{-1}\right.$ and $\left.\mathrm{T} 11=10^{-7} \mathrm{~s}^{-1}\right)$. Accordingly, at least, one of these two variables could be responsible for the angle variation. Further systematic experiments should be addressed to define the influence of grain size and strain rates on the angles formed by conjugate sets of CSBs. Also Tondi et al. (2006) documented a wide range of angles among the conjugate sets of natural CSBs. The aforementioned authors interpreted this variability as the consequence of slight different lithostatic pressures, which is actually consistent with the positive correlation we found between DBs angles and confining pressures 
Table 6

Summary of the rock components (2D measurements): pores (not comprehensive of micropores $<10 \mu \mathrm{m}$ ), grains and matrix.

\begin{tabular}{|c|c|c|c|c|c|c|c|c|c|}
\hline \multirow[t]{2}{*}{ Component [\%] } & \multicolumn{3}{|c|}{ Ma\#34 } & \multicolumn{2}{|c|}{ Orfento\#3 } & \multicolumn{2}{|l|}{$\mathrm{T} 1$} & \multicolumn{2}{|l|}{$\mathrm{T} 2$} \\
\hline & HR & $\mathrm{DZ}$ & CSB & HR & CSB & HR & CSB & HR & $\mathrm{CB}$ \\
\hline Porosity & 24.5 & 25.5 & 8.2 & 12.5 & 3.3 & 9.5 & 3.5 & 5 & 4 \\
\hline Cement + matrix & 5 & 42 & 86.3 & 24.2 & 72.7 & 28 & 37.5 & 26 & 46 \\
\hline Grains & 70.5 & 32.5 & 5.5 & 63.3 & 24 & 62.5 & 59 & 69 & 50 \\
\hline Grain-to-matrix ratio & 14.1 & 0.77 & 0.064 & 2.6 & 0.33 & 2.23 & 1.6 & 2.65 & 1.1 \\
\hline
\end{tabular}

and also in agreement with the experiments on sandstone of Baud et al. (2004) and on Saint Maximin limestone of Baud et al. (2009).

In agreement with Tondi et al. (2006) in the natural CSBs we observed randomly oriented PSs nucleating at the grain contacts. Throughout high-resolution FESEM observations we were also able to show tiny cracks at the grain contacts (in agreement with Rath et al., 2011 and Rustichelli et al., 2012). The presence of cracks within the inner part of one of the natural CSBs, as documented in this paper shows that they did not nucleate as disaggregation bands (sensu Fossen et al., 2007), and that they formed in a sediment that was already lithified. Furthermore, the Hertzian cracks locally reduced grain size and accelerated the pressure solution process (in agreement with Croizé et al., 2010c; Zhang et al., 2010). Dissolution channels developed for the leaching of fluids along pre-existing cracks. This is a further evidence that the deformation process took place in presence of fluids. Differently from Tondi (2007) and Rath et al. (2011), we did not document any porosity reduction induced by calcite precipitation in the carbonates surrounding the natural DBs.

Based upon the aforementioned data, we infer that the studied carbonates deformed in an open system (at least at an outcrop scale). Fluids may trigger chemical process such as pressure solution, the kinetics of this process depends on grain size and applied stress (e.g. Liteanu and Spiers, 2009), but it is strongly affected by fluids composition too. To decipher the influence of fluid chemical composition on the speed of the pressure solution, many experimental studies have been carried out (e.g. Zhang and Spiers, 2005; Croizé et al., 2010c; Zhang et al., 2010). The lack of calcite veins, in the study area, did not allow us to carry out fluid inclusions analysis, which could have given information on the fluid chemistry.

The PS and Hertzian cracking processes were a consequence of grain rotation and sliding and, hence, pore collapse (Fig. 20). The band-parallel PSs could grow (oblique to $\sigma_{1}$ ) within an already compacted rock. The dissolution of calcite determines accumulation of fine residual clay and/or organic matter, which, due to a lower frictional coefficient (Byerlee, 1978), may enhance slip and further dissolution (with formation of tail PSs, Fig. 20). Importantly, we did not find any correlation between the frequency of calcite mechanical twinning and the three typologies of natural structures (i.e. CSBs, CSB overprinted by PSs and CSBs overprinted by PSs and cataclastic material). This observation suggests that in nature, due to the very slow strain rates, twinning is a pressure-dependent process and not a strain-dependent one, as observed in the laboratory (see Vajdova et al., 2010). Twinning plays an important role in strain accommodation (Vajdova et al., 2010, in press), moreover, the qualitative observations we carried out on the laboratory DBs suggest that positive correlation exists between twinning density and confining pressure (Figs. 18-20). In addition, within the CSB we

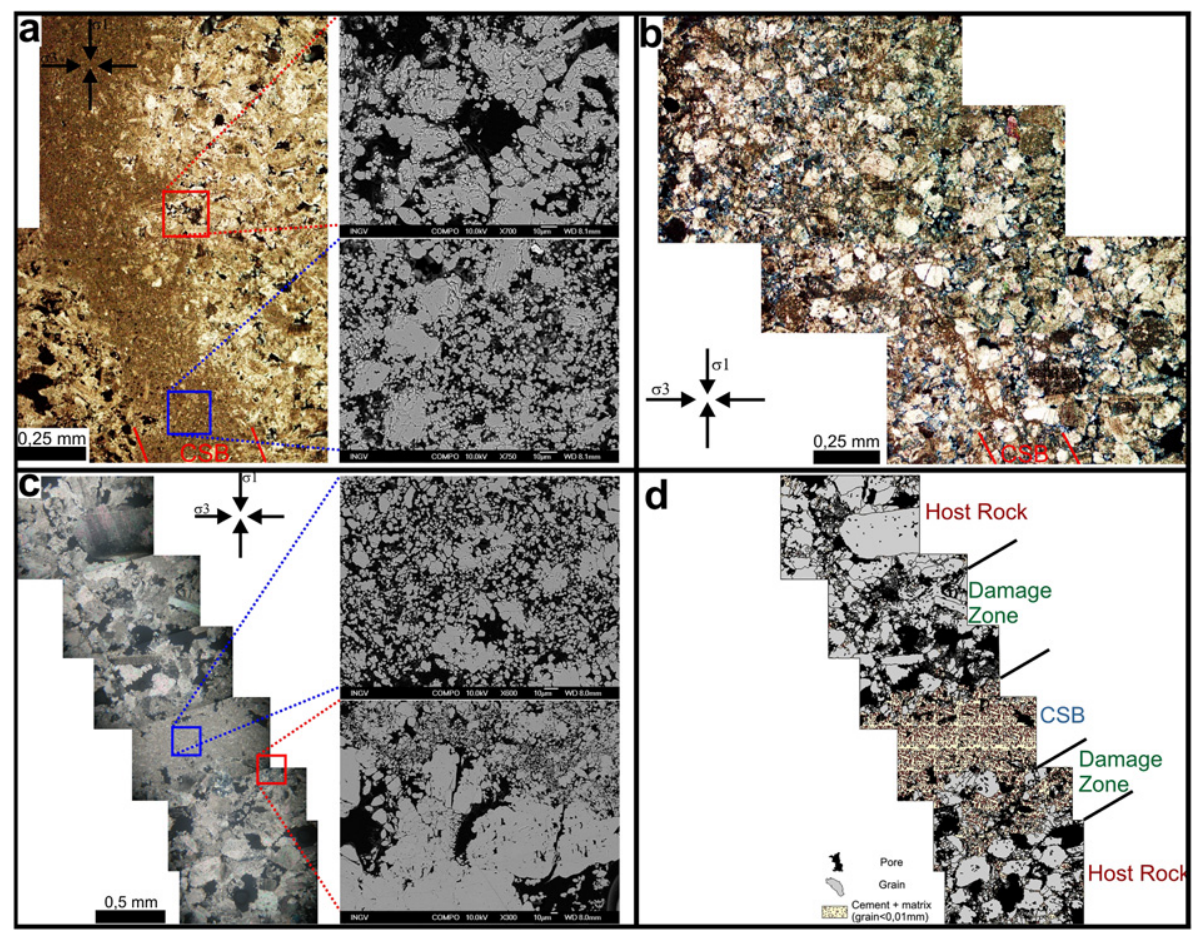

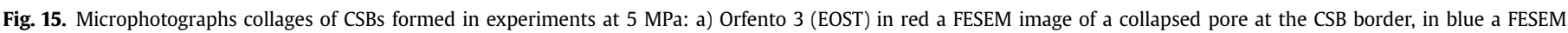

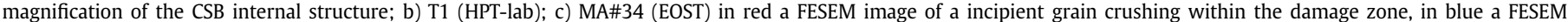

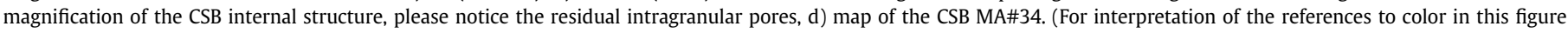
legend, the reader is referred to the web version of this article.) 


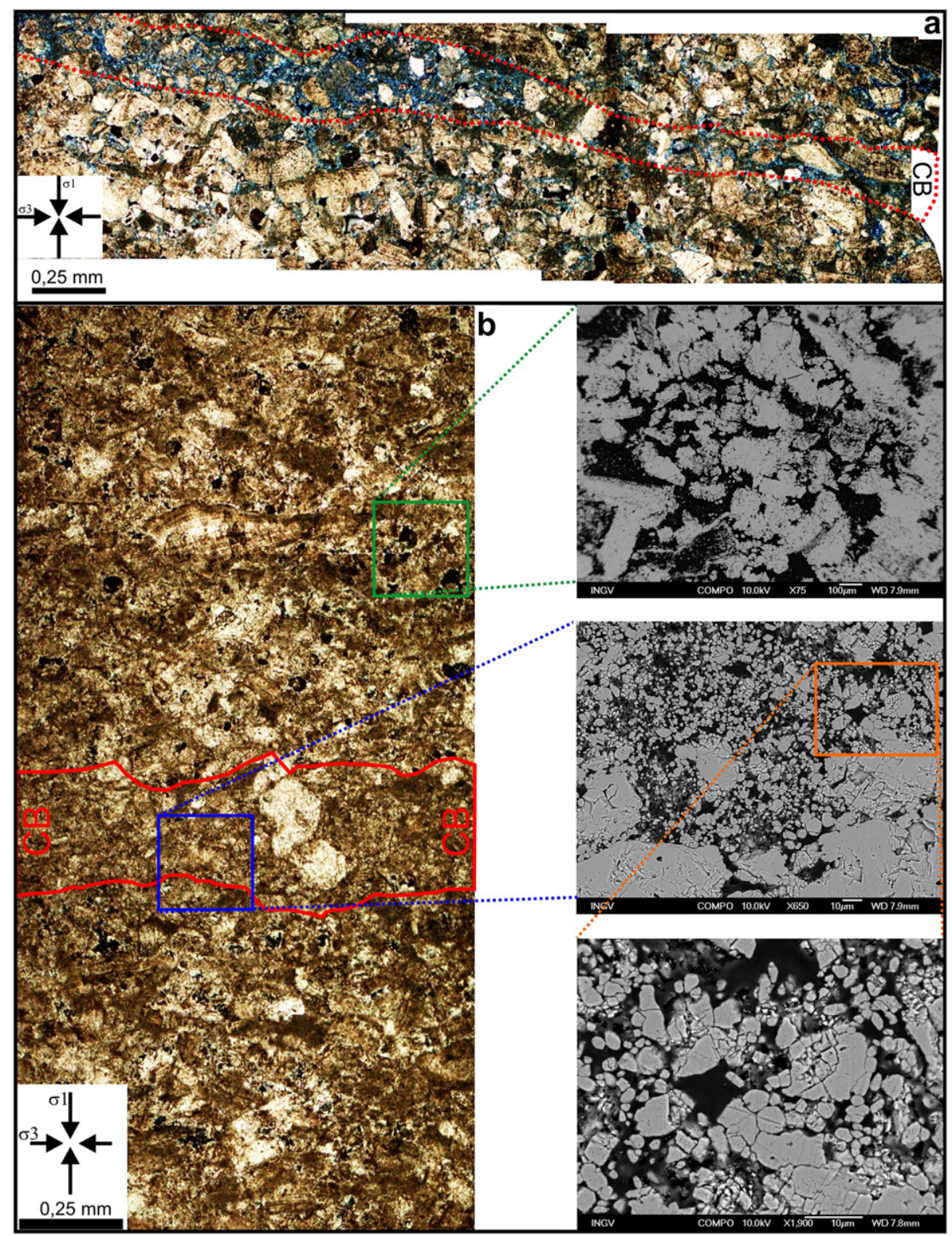

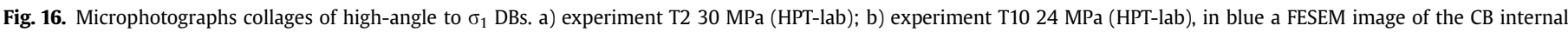

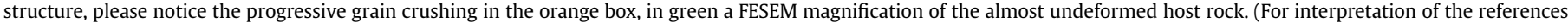
to color in this figure legend, the reader is referred to the web version of this article.)

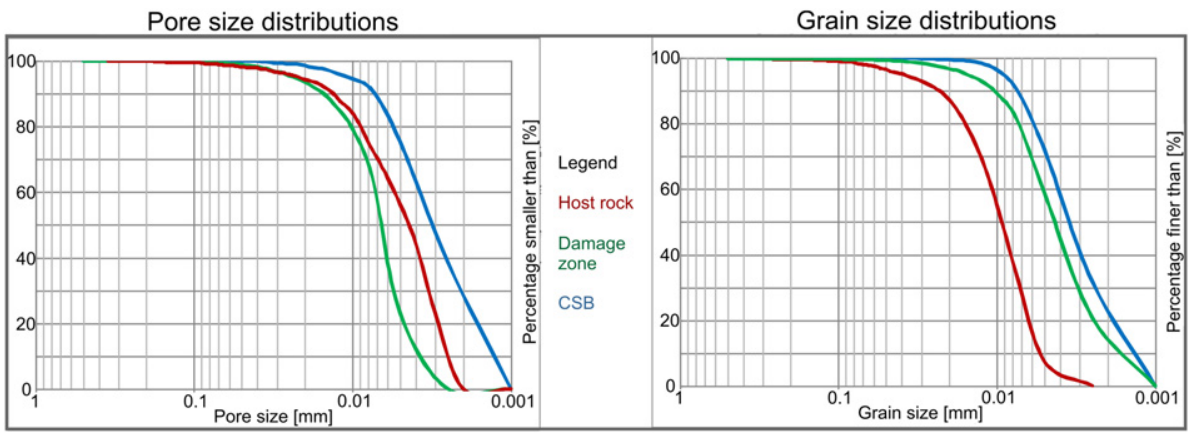

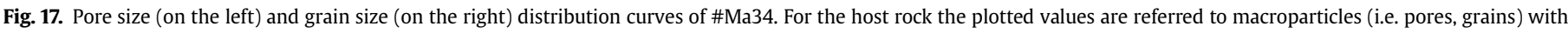
a longer diameter $>10 \mu \mathrm{m}$. On the contrary for both damage zone and CSB we measured the particles from FESEM images. 


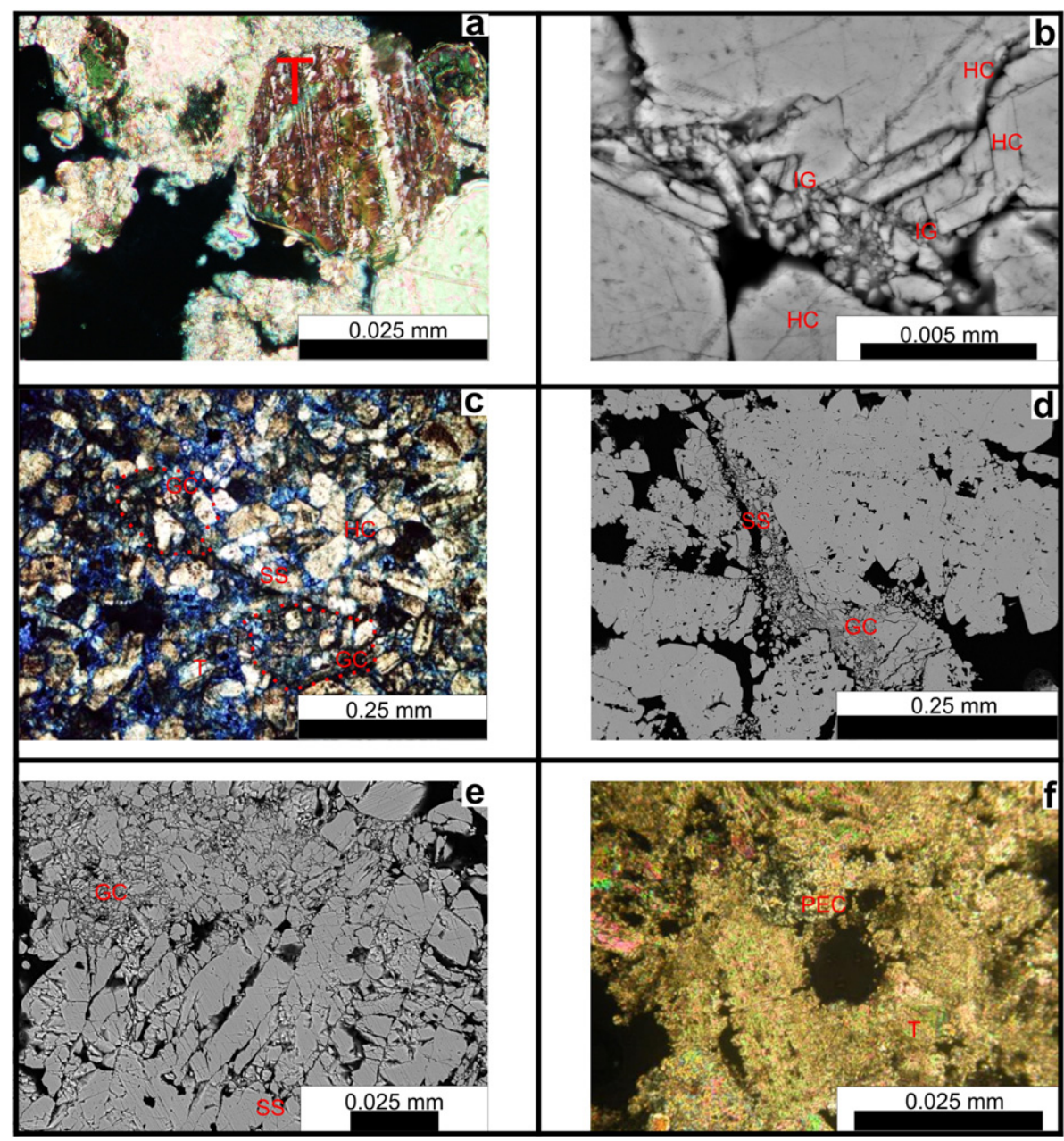

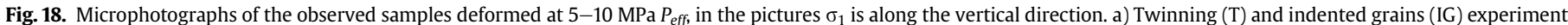

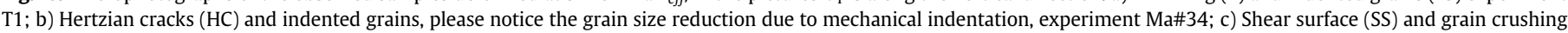

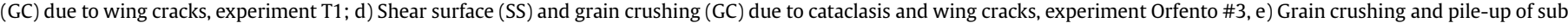
grains leaded by shear along two surfaces, experiment Orfento \#3; f) Pore-emanated cracks (PEC), experiment Ma\#14.

documented a more pronounced iso-orientation of the force chain with respect of the CB. Eichhubl et al. (2010) documented similar iso-orientation, and suggested that the grain movement associated with CSBs formation is more organized than grain movement within CBs. We also hypothesize that the wide range of force chain orientations, within the $\mathrm{CB}$, is the consequence of a better grain packing induced by grain size reduction, indeed a higher number of smaller grains promotes an isotropic distribution of the force chains.

In laboratory CSBs, randomly distributed grain crushing starts from Hertzian cracks (Zhang et al., 1990; and Brzesowsky et al., 2011) at the grain contacts, this process enhances the reduction of intergranular pore sizes by means of infilling of fine material and

Table 7

Summary of the rock components of the laboratory DBs: pores, grains and matrix.

\begin{tabular}{lclll}
\hline Experiment & $\begin{array}{l}\text { Crack for linear } \\
\text { intercepts } \\
\text { perpendicular } \\
\text { to } \sigma_{1}\left(\mathrm{~mm}^{-1}\right)\end{array}$ & $\begin{array}{l}\text { Crack for linear } \\
\text { intercepts } \\
\text { parallel to } \sigma_{1} \\
\left(\mathrm{~mm}^{-1}\right)\end{array}$ & $\begin{array}{l}\text { Crack area } \\
\text { per unit } \\
\text { volume } \mathrm{S}_{\mathrm{v}} \\
\left(\mathrm{mm}^{-2} / \mathrm{mm}^{-3}\right)\end{array}$ & $\begin{array}{l}\text { Anisotropy } \\
\text { factor } \Omega_{23}\end{array}$ \\
\hline CSB Ma\#34 & $81.1 \pm 11.9$ & $86.6 \pm 21.74$ & 164.6 & -0.053 \\
DZ Ma\#34 & $52 \pm 22.9$ & $56.7 \pm 28.06$ & 93.4 & -0.21 \\
CSB T1 & $59.74 \pm 16.8$ & $33.11 \pm 9.1$ & 108.1 & 0.39 \\
DZ T1 & $24.8 \pm 5.4$ & $15.9 \pm 4.4$ & 45.73 & 0.31 \\
\hline
\end{tabular}

particulate flow (Fig. 20). Twinned calcite grains are weaker and may localize shear surfaces. When shear localization occurs, the comminuted material facilitates the slip along discrete slip surfaces and the formation of wing cracks (Figs. 18 and 21; Baud et al., 2000; Vajdova et al., 2010). Other cracks can also originate from the stiffer intragranular pores as pore-emanated cracks (Vajdova et al., 2004).

The result of our crack counting on laboratory CSBs (Ma\#34 and T1) showed higher amount of damage in both the bands with respect to the host rocks (see Table 7). The calculated anisotropy factor in Ma\#34 is almost zero inside and outside the band, meaning that we dealt with an isotropic damage distribution, related to the localized high comminution degree within the CSB (Fig. 15c). The isotropic damage in the host rock is consistent with data of high porosity sandstone (Wu et al., 2000). The CSB in T1 has higher anisotropy factor values than the host rock, which shows isotropic damage. In this structure the isotropy can be due to the additional contribution of wing crack growth on its extentional quadrants, easily visible in Fig. 15b on the top of the dark shear band.

\subsection{Compaction bands}

The laboratory DB, nucleated at $P_{\text {eff }}=24 \mathrm{MPa}$ perpendicular to $\sigma_{1}$, consists of a continuous structure characterized by a fitted- 


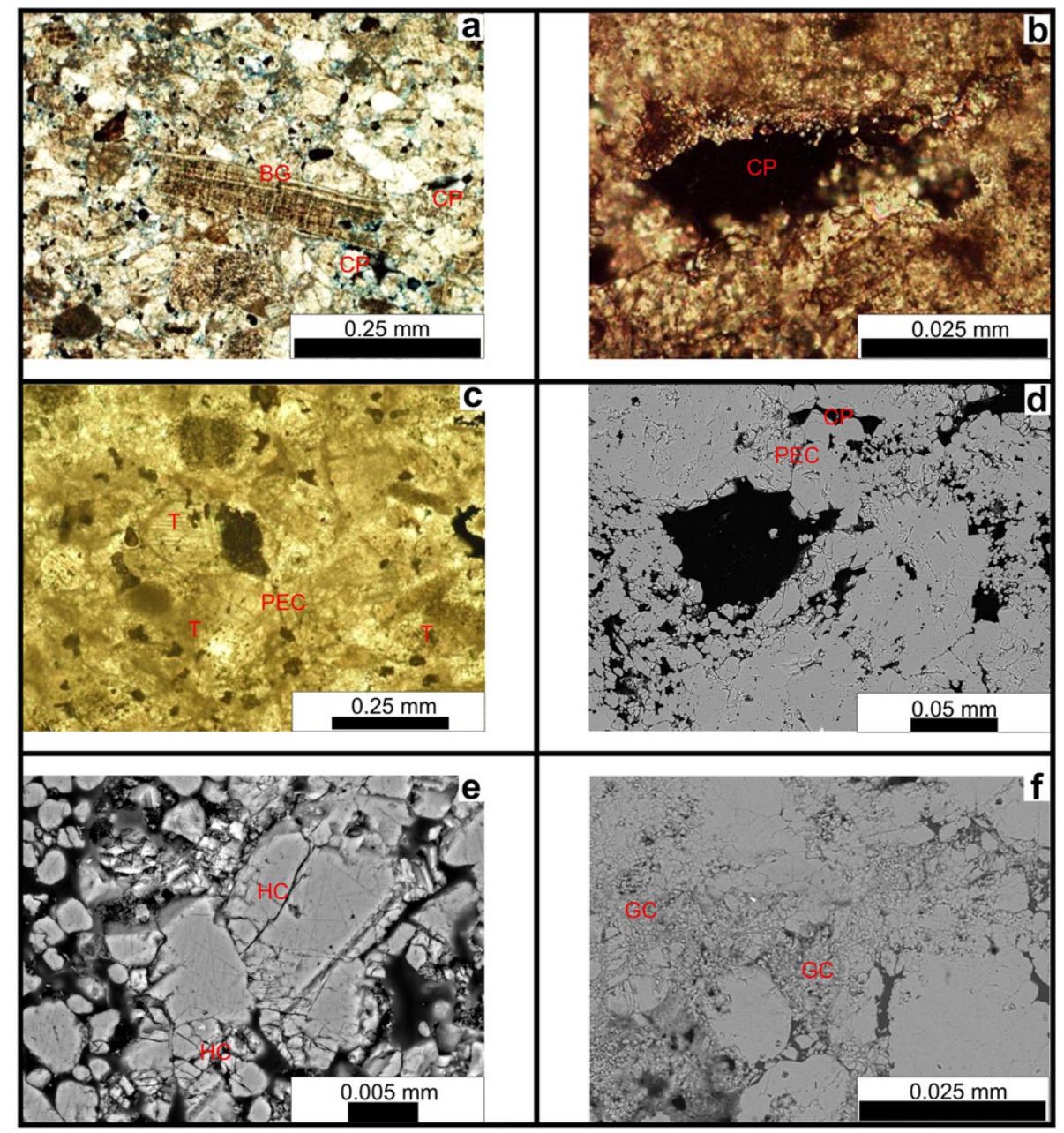

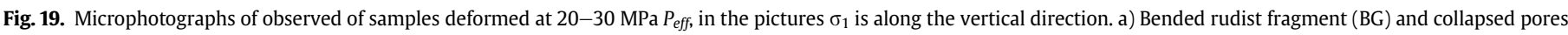

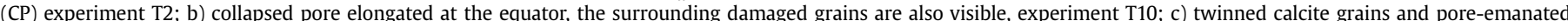

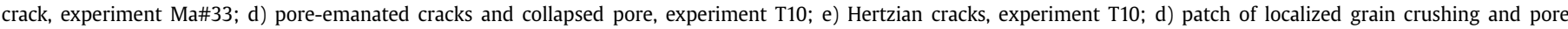
collapse, experiment Ma\#33.

fabric due to both pore and grain sizes reduction. The DB shows evidences of cataclastic pore collapse and grain crushing (Fig. 16), thus it can be compared with the compaction bands formed in sandstones by Baud et al. (2004). In the experiment Ma\#33 we documented discontinuous patches characterized by a similar fabric too (Fig. 19), due to an inferred incipient stage of compaction localization. Sedimentary heterogeneities (e.g. pore and grain size variations, preferred grain and pore orientations, increased clay or cement amount) can enhance the compaction localization (Baud et al., 2004; Stanchits et al., 2009; Charalampidou et al., 2011; Rustichelli et al., 2012). Based upon our data, we suggest that since the sample S18 Low. (T10) was coarser, and characterized by a bigger pore size than the sample S18 Upp. (Ma\#33) it was more prone to compaction localization because smaller pores are more regular in shape and, hence, stiffer. The band in sample T10 presents a texture that is comparable with the natural CBs (Fig. 7) and we therefore concluded that this structure is a compaction band. To our knowledge, the only laboratory study (Baxevanis et al., 2006) reporting compactions bands in a carbonate rock was performed on Tuffeau de Maastricht calcarenite. While Baxevanis et al. (2006) showed convincing evidences of compaction localization in their laboratory deformed samples, it was however unclear in their study if CBs could actually be observed in the field in the Tuffeau de Maastricht formations. Our analyses of CBs observed for the first time both in the field and in the laboratory-deformed samples provided a base to systematically study the development of these structures in grainstones.

The crack counting on the laboratory CB (T10) showed higher damage in the band with respect to the host rock (see Table 7). The anisotropy factor is almost negligible in the host rock if compared with the $\mathrm{CB}$, which has a high anisotropy. We interpreted this data due to the lack of shear within the band and a more dominant pore collapse with respect to the particulate flow. The second high-angle to $\sigma_{1}$ DB formed at $P_{\text {eff }}=30 \mathrm{MPa}$, shows similar angle and petrophysical properties (i.e. grain size and pore size reduction with respect to the host rock) to those one developed in dry experiments on the St. Maximin limestone (Baud et al., 2009) and to the natural "shear-enhanced compaction bands" documented for sandstones (Aydin and Ahmadov, 2009; Eichhubl et al., 2010). For the aforementioned reason, we refer to this structure as a shear-enhanced compaction band.

The effective pressures at which we formed the two high-angle (to $\sigma_{1}$ ) structures (24 and $30 \mathrm{MPa}$ ) raises a question on the burial condition at which the natural CBs of Madonna della Mazza Quarry nucleated. In fact, according to Tondi et al. (2006), they are the oldest set of DBs of the quarry, but the experimental results presented in this paper show that, with the present host rock characteristics (i.e. porosity, grain size, cement amount), CBs need 


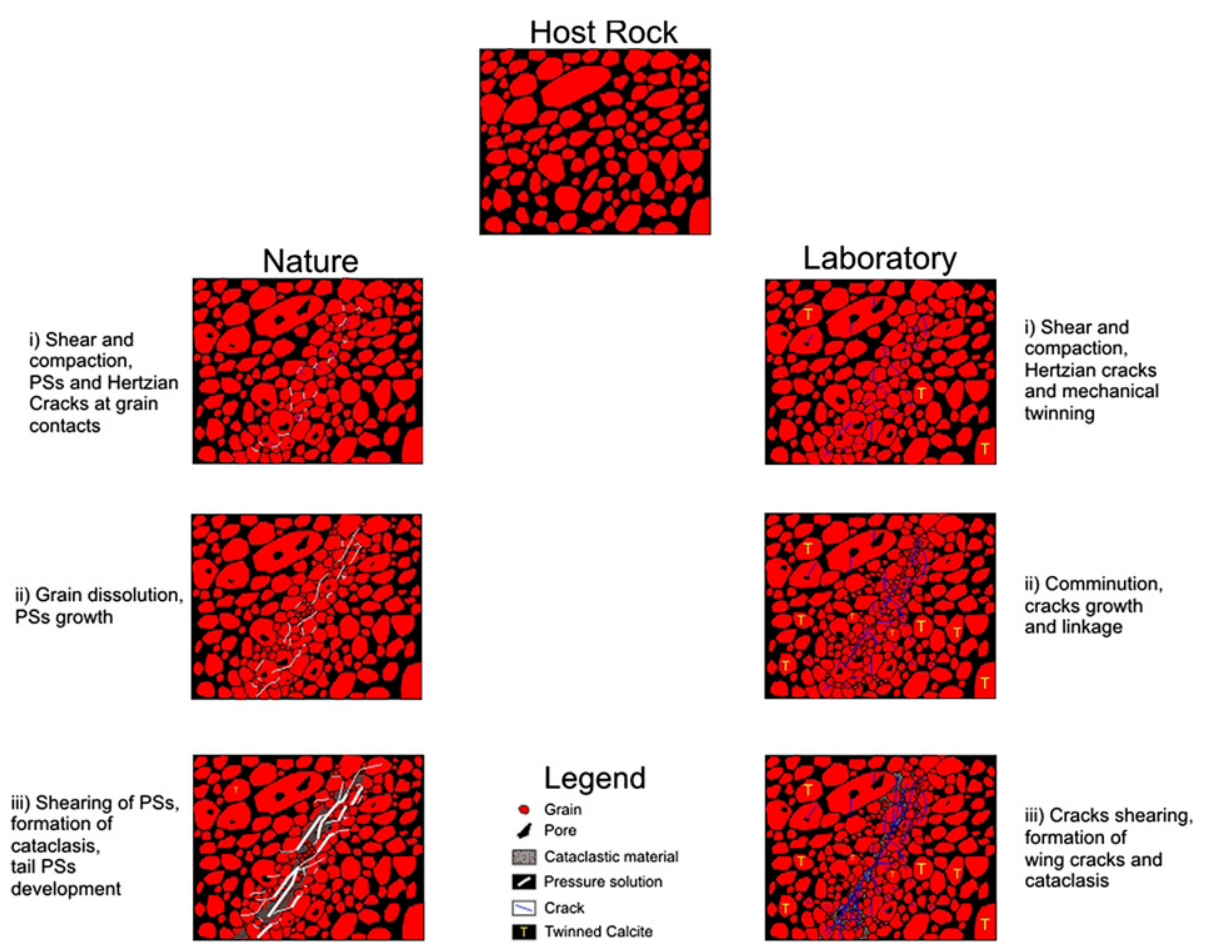

Fig. 20. Conceptual model of natural (on left) and laboratory (on right) CSBs nucleation and development.

higher confining pressure to form with respect to the CSBs. According to Tondi et al. (2006), natural CBs localize within the coarser beds, moreover Rustichelli et al. (submitted for publication) show how coarser better-sorted grainstones are less cemented than the finer ones. Accordingly, during burial the coarser beds could have preserved their skeleton porosity (up to $47 \%$, according to Tondi et al., 2006) for a longer time with respect to the finer ones. If so, these coarser beds could have kept the product $P^{*} \propto(\phi R)^{-0.7}$ ( $\phi=$ porosity and $R=$ grain radius $(\mathrm{mm})$; Baud et al., 2009), on a lower value with respect to the finer and more cemented beds and, therefore, nucleate CBs prior to CSBs. This hypothesis is also

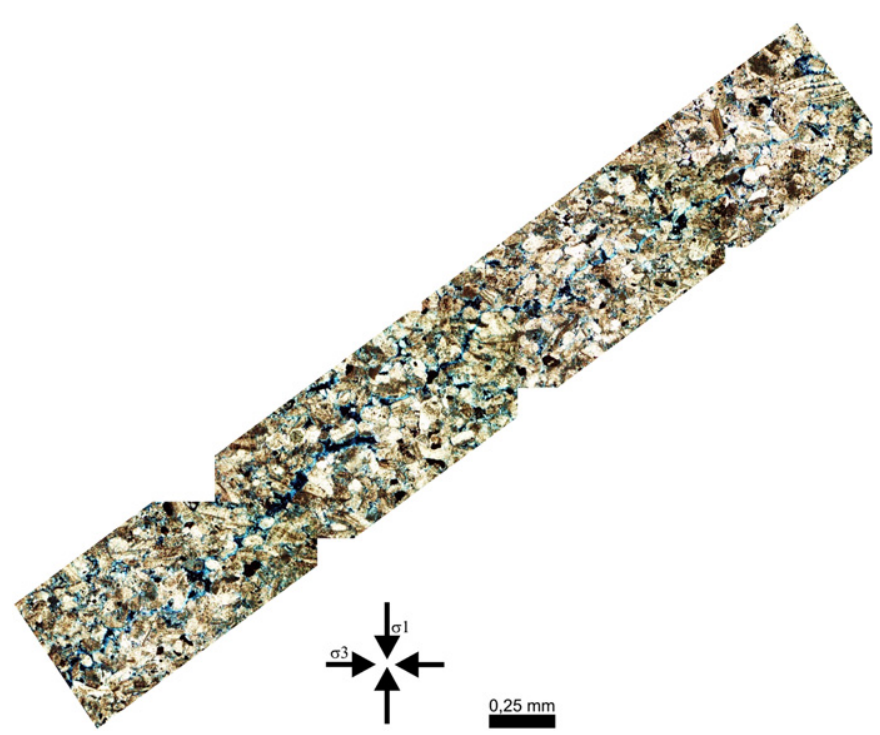

Fig. 21. Possible dilatant shear band formed during the experiment T7 at $5 \mathrm{MPa} P_{\text {eff. }}$ coherent with the mechanical data, which show that higher values of differential stress are needed to form CSBs than CBs (in agreement with Bésuelle et al., 2003; Baud et al., 2004 and Fossen et al., 2011).

\subsection{Dilatant shear bands?}

In the set of experiments (T7; T11 and T14) performed on the sample S19 at $P_{\text {eff }}=5 \mathrm{MPa}$ with a strain rate of $10^{-7} \mathrm{~s}^{-1}$, we observed evidence of a slight dilation associated with axial strains up to $0.65 \%$. This behavior was really unexpected because it differs from that depicted by the analog experiment T12 $\left(P_{\text {eff }}=5 \mathrm{MPa}\right.$; strain rate of $10^{-7} \mathrm{~s}^{-1}$; axial strain of $0.9 \%$, sample $\left.\mathrm{S} 18\right)$. The discrepancy between wet and dry experiments suggests that some chemical process (i.e. pressure solution, stress-corrosion crack growth) occurred. Since pressure solution would likely lead to a compactant behavior, the possible cause for the observed dilatancy could be stress-corrosion cracking. Heap et al. (2009) documented brittle creep in sandstones at similar strain rates, and also found that subcritical crack growth is very sensitive to effective pressure. This would explain why we did not observe major differences between experiments performed at higher pressures, at low and high strain rates. One question still needs to be answered: why was dilatancy not also observed in the experiment T12? A possible reason could be related to the pore size in $\mathrm{S} 19(20 \mu \mathrm{m})$ being three times smaller than in $\mathrm{S} 18(60 \mu \mathrm{m})$ and its influence on subcritical crack growth. Since there is to our knowledge a paucity of data on stress-corrosion and creep in porous limestone (Liteanu and Spiers, 2009; Croizé et al., 2010c), more work is needed to confirm our observations. The observed dilatancy is however supported by the microstructural observations carried out on sample T7 (Fig. 21). In this sample, we documented a zone of localized porosity increase, which rarely crosscuts the grains. This structure can be compared to the dilatant shear bands described by Aydin et al. (2006) and Fossen et al. (2007). 


\section{Conclusions}

The present study compares natural and laboratory deformation bands formed in the Upper Cretaceous carbonate grainstones of the Orfento formation. The aim was to constrain the pressure conditions at which natural deformation bands nucleate, and detail the micromechanisms responsible of their formation and development. The microstructural analysis of natural structures allowed us to define the spatial distribution of PSs within the DBs, to quantify the evolution of their spatial anisotropy factor and compute both grain size and pore size distributions. We also found tiny Hertzian cracks at the grain contacts within the natural CSB, which is consistent with these structures enhancing pressure solution processes by locally decreasing the grain size. On the surface of some grains, we also observed dissolution channels developed for the leaching of fluids along pre-existing cracks, which is a further evidence that natural deformation bands formed under wet conditions.

Two sets of triaxial compression experiments were carried out. Most of the deformed samples displayed a shear-enhanced compaction behavior and often showed strain hardening at the higher confining pressures. Only one of the deformed samples showed dilation at low strain rates. The comparison between wet (this study) and dry (Baud et al., 2009) experimental data indicated the weakening effect of water on the strength of these carbonates. Compactive shear bands, at different angles with respect to the $\sigma_{1}$, nucleated mainly during the low-confining pressure experiments. A dilatant shear band was also observed. Compaction localization occurred and a discrete compaction band was documented.

The petrophysical properties of the laboratory deformation bands have been studied by means of detailed microstructural analyses. We documented Hertzian cracks starting from the grain contacts, which determined the infilling of intergranular pores with fine material and enhanced particulate flow. The comminuted material promoted shear localization and discrete slip surfaces with wing cracks at their tips developed. Other cracks originated from the stiffer intraganular pores, the frequency of calcite mechanical twinning showed a positive correlation with the increasing of the confining pressure.

By comparing natural and laboratory DBs we were able to constrain the pressure conditions at which natural CSBs formed $(<10 \mathrm{MPa})$. It was also possible to understand the geological reasons that allowed natural CBs in Madonna della Mazza quarry to develop before CSBs.

In summary, CSBs formation presents important differences among natural and laboratory conditions: i) Particulate flow, in nature, takes place without significant grain crushing; ii) grain contacts in nature have a more ductile response with respect to the laboratory experiments. Indeed Liteanu and Spiers (2009) documented intergranular pressure solution of calcite in laboratory only after 30 days at $80{ }^{\circ} \mathrm{C}$. When grain crushing occurs in nature, it enhances the process of pressure solution; iii) in the natural deformation, after shear localization, tail pressure solution can form at the contractional quadrants of the sheared parental structures. On the contrary, in laboratory conditions, wing cracks nucleate at the extensional quadrant of the slip surfaces.

By means of this study we gained new insights into the mechanisms occurring in nature and laboratory and key results to better assess the role of intergranular PSs at shallow depths.

\section{Acknowledgments}

This work has been supported by the MIUR, PRIN 2009 (National Coordinator E. Tondi) and the Reservoir Characterization Project www.rechproject.com. P. Baud was partially funded by the CAPES-
COFECUB program. A.C. is very grateful to C.J. Peach, B.A. Verberne and the whole staff of HPT-Lab for their technical support and the fruitful discussions during the deformation experiments. The authors are also grateful to A. Cavallo and S. Mollo from INGV of Rome for their help during the FESEM and porosity analyses respectively. We thank F.M. de Grisogono for his help on x-ray diffraction analyses. We acknowledge the comments and suggestions provided by the editor R. Toussaint and the two anonymous reviewers, who sensitively improved both quality and legibility of this paper.

\section{References}

Agosta, F., Alessandroni, M., Antonellini, M., Tondi, E., Giorgioni, M., 2010. From fractures to flow: a field-based quantitative analysis of an outcropping carbonate reservoir. Tectonophysics 490, 197-213. doi:10.1016/j.tecto.2010.05.005.

Agosta, F., Alessandroni, M., Tondi, E., Aydin, A., 2009. Oblique-slip normal faulting along the northern edge of the Majella anticline: inferences on hydrocarbon migration and accumulation. Journal of Structural Geology 31, 690-774.

Agosta, F., Aydin, A., 2006. Architecture and deformation mechanism of a basinbounding normal fault in Mesozoic platform carbonates, central Italy. Journa of Structural Geology 28, 1445-1467.

Alvarez, W., Engelder, T., Geiser, P.A., 1978. Classification of solution cleavage in pelagic limestones. Geology 6, 263-266.

Antonellini, M., Aydin, A., 1994. Effect of faulting on fluid flow in porous sandstones: petrophysical properties. AAPG Bulletin 78, 355-377. doi:10.1016/01489062(96)83981-7.

Antonellini, M., Aydin, A., Pollard, D., 1994. Microstructure of deformation bands in porous sandstones at Arches National Park, Utah. Journal of Structural Geology 16 (7), 941-959.

Antonellini, M., Tondi, E., Agosta, F., Aydin, A., Cello, G., 2008. Failure modes in deepwater carbonates and their impact for fault development: Majella Mountain Central Apennines, Italy. Marine and Petroleum Geology 25, 1074-1096. doi:10.1016/j.marpetgeo.2007.10.008.

Aydin, A., 1978. Small faults formed as deformation bands in sandstone. Pure and Applied Geophysics 116, 913-930. doi:10.1007/BF00876546.

Aydin, A., Ahmadov, R., 2009. Bed-parallel compaction bands in aeolian sandstone: their identification and characterization. Tectonophysics 479, 277-284 doi:10.1016/j.tecto.2009.08.033.

Aydin, A., Antonellini, M., Tondi, E., Agosta, F., 2010. Deformation along the leading edge of the Majella thrust sheet in central Italy. Journal of Structural Geology 32, 1291-1304. doi:10.1016/j.jsg.2008.10.005.

Aydin, A., Borja, R.I., Eichhubl, P., 2006. Geological and mathematical framework for failure modes in granular rock. Journal of Structural Geology 28, 83-98. doi:10.1016/j.jsg.2005.07.008.

Ashby, M.F., Sammis, C.G., 1990. The damage mechanics of brittle solids in compression. Pure and Appled Geophysics 133, 489-521.

Baud, P., Klein, E., Wong, T.-f, 2004. Compaction localization in porous sandstones: spatial evolution of damage and acoustic emission activity. Journal of Structura Geology 26, 603-624.

Baud, P., Schubnel, A., Wong, T.-f, 2000. Dilatancy, compaction and failure mode in Solnhofen limestone. Journal of Geophysical Research 195, 19289-19303.

Baud, P., Vinciguerra, S., David, C., Cavallo, A., Walker, E., Reuschle, T., 2009. Compaction and failure in high porosity carbonates: mechanical data and microstructural observations. Pure and Applied Geophysics 166, 869-898. doi:10.1007/s00024-009-0493-2.

Baxevanis, T., Papamichos, E., Flornes, O., Larsen, I., 2006. Compaction bands and induced permeability reduction in Tuffeau de Maastricht calcarenite. Acta Geotechnica 1, 123-135. doi:10.1007/s11440-006-0011-y.

Bésuelle, P., Baud, P., Wong, T.-f, 2003. Failure mode and spatial distribution of damage in Rothbach Sandstone in brittle-ductile transition. Pure and Applied Geophysics 160, 851-868.

Brzesowsky, R.H., Spiers, C.J., Peach, C.J., Hangx, S.J.T., 2011. Failure behavior of single sand grains: theory versus experiment. Journal of Geophysical Research 116 B06205. doi:10.1029/2010JB008120.

Byerlee, J., 1978. Friction of rocks. Pure and Appled Geophysics 116, 615-626. doi: $10.1007 /$ BF00876528.

Casadio, M., Elmi, C., 2006. In: Pitagora Editrice (Ed.), Il manuale del geologo, ISBN 88-371-1463-X, pp. 182-186.

Charalampidou, E.-M., Hall, S.A., Stanchits, S., Lewis, H., Viggiani, G., 2011. Characterization of shear and compaction bands in a porous sandstone deformed under triaxial compression. Tectono Physics 503, 8-17. doi:10.1016/ j.tecto.2010.09.032.

Choquette, P.W., Pray, L.C., 1970. Geologic nomenclature and classification of porosity in sedimentary carbonates. AAPG Bulletin 54 (2), 207-244.

Croizé, D., Bjørlykke, K., Jahren, J., Renard, F., 2010a. Experimental mechanical and chemical compaction of carbonate sand. Journal of Geophysical Research 115 B11204. doi:10.1029/2010JB007697.

Croizé, D., Ehrenberg, S.N., Bjørlykke, K., Renard, F., Jahren, J., 2010b. Petrophysical properties of bioclastic platform carbonates: implications for porosity controls during burial. Marine and Petroleum Geology 27, 1765-1774. 
Croizé, D., Renard, F., Bjørlykke, K., Dysthe, D.K., 2010c. Experimental calcite dissolution under stress: evolution of grain contact microstructure during pressure solution creep. Journal of Geophysical Research 115, B09207. doi:10.1029/2010JB000869.

Curran, J.H., Carroll, M.M., 1979. Shear stress enhancement of void compaction. Journal of Geophysical Research 84, 1105-1112.

Dautriat, J., Gland, N., Dimanov, A., Raphanel, J., 2011. Hydromechanical behavior of heterogeneous carbonate rock under proportional triaxial loadings. Journal of Geophysical Research 116 (b01205), 26. doi:10.1029/2009JB000830.

Dunham, R.J., 1962. Classification of carbonate rocks according to depositional texture. In: Ham, W.E. (Ed.), Classification of Carbonate Rocks: American Association of Petroleum Geologists Memoir, pp. 108-121.

Eichhubl, P., Hooker, J.N., Laubach, S.E., 2010. Pure and shear-enhanced compaction bands in Aztec Sandstone. Journal of Structural Geology Volume 32 1873-1886.

Engelder, J.T., 1974. Cataclasis and the generation of fault gouge. Geological Society of America Bulletin 85 (10), 1515-1522. doi:10.1130/0016-7606(1974) $85<1515$ : catgof $>2.0$. co; 2

Fabre, D., Gustkiewicz, J., 1997. Poroelastic properties of limestones and sandstones under hydrostatic conditions. International Journal of Rock Mechanics and Mining Sciences 34 (1), 127-134.

Faulkner, D.R., Jackson, C.A.L., Lunn, R.J., Schlische, R.W., Shipton, Z.K. Wibberley, C.A.J., Withjack, M.O., 2010. A review of recent developments concerning the structure, mechanics and fluid flow properties of fault zones. Journal of Structural Geology 32, 1557-1575. doi:10.1016/j.jsg.2010.06.009.

Fossen, H., Schultz, R.A., Torabi, A., 2011. Conditions and implications for compaction band formation in the Navajo Sandstone, Utah. Journal of Structura Geology 33, 1477-1490. doi:10.1016/j.jsg.2011.08.001.

Fossen, H., Schultz, R.A., Shipton, Z.K., Mair, K., 2007. Deformation bands in sandstone: a review. Journal of the Geological Society 164, 755-769. doi:10.1144/ 0016-76492006-036.

Fruth, J., L S, Orme, G.R., Donath, F.A., 1966. Experimental compaction effects in carbonate sediments. Journal of Sedimentary Petrology 36 (3), 747-754.

Ghisetti, F., Vezzani, L., 2002. Normal faulting, extension and uplift in the outer thrust belt of the central Apennines (Italy): role of the Caramanico fault. Basin Research 14, 225-236.

Groshong, R.H., 1988. Low-temperature deformation mechanisms and their interpretation. Geological Society of America Bulletin 100, 1329-1360.

Heap, M.J., Baud, P., Meredith, P.G., Bell, A.F., Main, I.G., 2009. Time-dependent brittle creep in Darley Dale sandstone. Journal of Geophysical Research 114 B07203. doi:10.1029/2008jb006212.

Liteanu, E., Spiers, C.J., 2009. Influence of pore fluid salt content on compaction creep of calcite aggregates in the presence of supercritical $\mathrm{CO}_{2}$. Chemical Geology 265, 134-147. doi:10.1016/i.chemgeo.2008.12.010.

Marchegiani, L., Van Dijk, J.P., Gillespie, P.A., Tondi, E., Cello, G., 2006. Scaling properties of the dimensional and spatial characteristics of fault and fracture systems in the Majella Mountain, central Italy. In: Cello, G., Malamud, B. (Eds.) Fractal Analysis for Natural Hazards. Geological Society of London, Special Publication, 261, pp. 113-131. doi:10.1144/GSL.SP.2006.261.01.09.

Mutti, M., 1995. Porosity development and diagenesis in the Orfento supersequence and its bounding unconformities (Upper Cretaceous, Montagna della Majella, Italy). In: Budd, D.A., Saller, A.H., Harris, P.M. (Eds.), Unconformities and Porosity in Carbonate Strata. AAPG, pp. 141-158.

Mutti, M., Bernoulli, D., Eberli, G.P., Vecsei, A., 1996. Depositional geometries and facies associations in an upper Cretaceous prograding carbonate platform margin (Orfento supersequence, Maiella, Italy). Journal of Sedimentary Research 66 (4), 749-765.

Paterson, M.S., Wong, T-f, 2004. Experimental Rock Deformation; the Brittle Field, second ed.. Springer-Verlag, Berlin, Federal Republic of Germany.

Potyondy, D.O., Cundall, P.A., 2004. A bonded-particle model for rock. International Journal of Rock Mechanics and Mining Sciences 41 (8), 1329e1364.

Rath, A., Exner, U., Tschegg, C., Grasemann, B., Laner, R., Draganits, E., 2011. Diagenetic control of deformation mechanisms in deformation bands in a carbonate grainstone. AAPG Bulletin 95 (8), 1369-1381.

Renner, J., Rummel, F., 1996. The effect of experimental and microstructura parameters on the transition from brittle failure to cataclastic flow of carbonate rocks. Tectonophysics 258 (1-4), 151-169. doi:10.1016/00401951(95)00192-1.

Risnes, R., Madland, M.V., Hole, M., Kwabiah, N.K., 2005. Water weakening of chalk -mechanical effects of water-glycol mixtures. Journal Petroleum Science Engeneering 48, 21-36.
Rustichelli, A., 2010. Mechanical stratigraphy of carbonate rocks: examples from the Maiella Mountain (central Italy) and the Granada Basin (southern Spain). Ph.D thesis, University of Camerino.

Rustichelli, A., Tondi, E., Agosta, F., Cilona, A., Giorgioni, M., 2012. Development and distribution of bed-parallel compaction bands and pressure solution seams in the Bolognano Formation carbonates (Majella Mountain, Italy). Journal of Structural Geology. doi:10.1016/j.jsg.2012.01.007.

Rustichelli, A., Tondi, E., Agosta, F., Di Celma C., Giorgioni, M., (submitted for publication). Sedimentological and diagenetic controls on pore network characteristics of Oligo-Miocene ramp carbonates (Majella Mountain, central Italy). AAPG Bulletin.

Rutter, E.H., 1983. Pressure solution in nature, theory and experiment. Geological Society of London Journal 140, 725-740.

Scisciani, V., Tavarnelli, E., Calamita, F., 2002. The interaction of extensional and contractional deformation in the outer zones of the Central Apennines, Italy. Journal of Structural Geology 24, 1647-1658. doi:10.1016/S0191-8141(01) 00164-X.

Shipton, Z.K., Cowie, P.A., 2001. Damage zone and slip-surface evolution over $m$ to $\mathrm{km}$ scales in high-porosity Navajo sandstone, Utah. Journal of Structural Geology 23, 1825-1844.

Stanchits, S., Fortin, J., Gueguen, Y., Dresen, G., 2009. Initiation and propagation of compaction bands in dry and wet Bentheim sandstone. Pure and Applied Geophysics 166 (5-7), 843-868. doi:10.1007/s00024-009-0478-1.

Teufel, L.W., Rhett, D.H., Farrell, H.E., 1991. Effect of reservoir depletion and pore pressure drawdown on in situ stress and deformation in the Ekofisk field, North Sea. Proceedings of US Rock Mechanics Symposium 32, 63-72.

Tondi, E., 2007. Nucleation, development and petrophysical properties of faults in carbonate grainstones: evidence from the San Vito Lo Capo peninsula (Sicily, Italy). Journal of Structural Geology 29, 614-628. doi:10.1016/j.jsg.2006.11.006.

Tondi, E. Antonellini, M., Aydin, A, Marchegiani, L, Cello, G, 2006. The role of deformation bands, stylolites and sheared stylolites in fault development in carbonate grainstones of Majella Mountain, Italy. Journal of Structural Geology 28, 376-391.

Tondi, E., Cilona, A., Agosta, F., Aydin, A., Rustichelli, A., Renda, P., Giunta, G., 2012. Growth processes, dimensional parameters and scaling relationships of two conjugate sets of compactive shear bands in porous carbonate grainstones, Favignana Island, Italy. Journal of Structural Geology 37, 53-64.

Underwood, E.E., 1970. Quantitative Stereology: Reading. Adison Wesley, p. 274.

Vajdova, V., Baud, P., Wong, T.-f, 2004. Compaction, dilatancy and failure in porous carbonate rocks. Journal of Geophysical Research 109, B10406. doi:10.1029/ 2003JB002942.

Vajdova, V., Baud, P., Wu, L., Wong T.-f., in press. Micromechanics of inelastic compaction in two allochemical limestones. Journal of Structural Geology, 37.

Vajdova, V., Zhu, W., Chen, T.M.N., Wong, T.F., 2010. Micromechanics of brittle faulting and cataclastic flow in Tavel limestone. Journal of Structural Geology 32, 1158-1169. doi:10.1016/j.jsg.2010.07.007.

Vezzani, L., Ghisetti, F., 1998. Carta Geologica Dell'Abruzzo. S.EL.CA, Firenze.

Vecsei, A., Aggradation un Progradation eines karbonatplatform-Randes: Kreide bis Mittleres Tertiär der Montagna della Maiella Abruzzen. In: Mitteilungen aus dem Geologischen Institut der Eidgenössischen Technischen Hochschule und der Universitat Zürich. Neue Folge 294.

Wong, T.-f, Baud, P., 1999. Mechanical compaction of porous sandstone, oil and gas science and technology. Revue de l'Institut Français du Pétrole 54, 715-727.

Wong, T.-f., David, C., Zhu, W., 1997. The transition from brittle faulting to cataclastic flow in porous sandstones: mechanical deformation. Journal of Geophysical Research 102, 3009-3025.

Wu, X.Y., Baud, P., Wong, T.-f, 2000. Micromechanics of compressive failure and spatial 1005 evolution of anisotropic damage in Darley Dale sandstone. International Journal of Rock Mechanics and Mining Science 37 (1006), $143-160$.

Zhang, X., Spiers, C.J., Peach, C.J., 2010. Compaction creep of wet granular calcite by pressure solution at $28^{\circ} \mathrm{C}-150^{\circ} \mathrm{C}$. Journal of Geophysical Research 115, B09217.

Zhang, J., Wong, T.-f., Davis, M.D., 1990. Micromechanics of pressure induced grain crushing in porous rocks. Journal of Geophysical Research 95, 341-352.

Zhang, X., Spiers, C.J., 2005. Compaction of granular calcite by pressure solution at room temperature and effects of pore fluid chemistry. International Journal of Rock Mechanics and Mining Sciences 42, 950-960.

Zhu, W., Baud, P., Wong, T.-f, 2010. Micromechanics of cataclastic pore collapse in limestone. Journal of Geophysical. Research 115, B04405. doi:10.1029/ 2009JB006610. 